UNIVERSITY OF SÃO PAULO

DEPARTMENT OF MINING AND PETROLEUM ENGINEERING

ALBERTO MARIO PEREZ VENERA

ANALYSIS OF RISKS ASSOCIATED WITH EXPLORATION WELL DRILLING IN THE BRAZILIAN EQUATORIAL MARGIN

São Paulo

2019 


\section{ANALYSIS OF RISKS ASSOCIATED WITH EXPLORATION WELL DRILLING IN THE BRAZILIAN EQUATORIAL MARGIN}

Master's thesis submitted to the Polytechnic School of the University of São Paulo in partial fulfillment of the requirements for the degree of Master of Science.

Concentration Area:

Mineral Engineering

Supervisor:

Prof. Dr. Ronaldo Carrion

São Paulo

2019 
Autorizo a reprodução e divulgação total ou parcial deste trabalho, por qualquer meio convencional ou eletrônico, para fins de estudo e pesquisa, desde que citada a fonte.

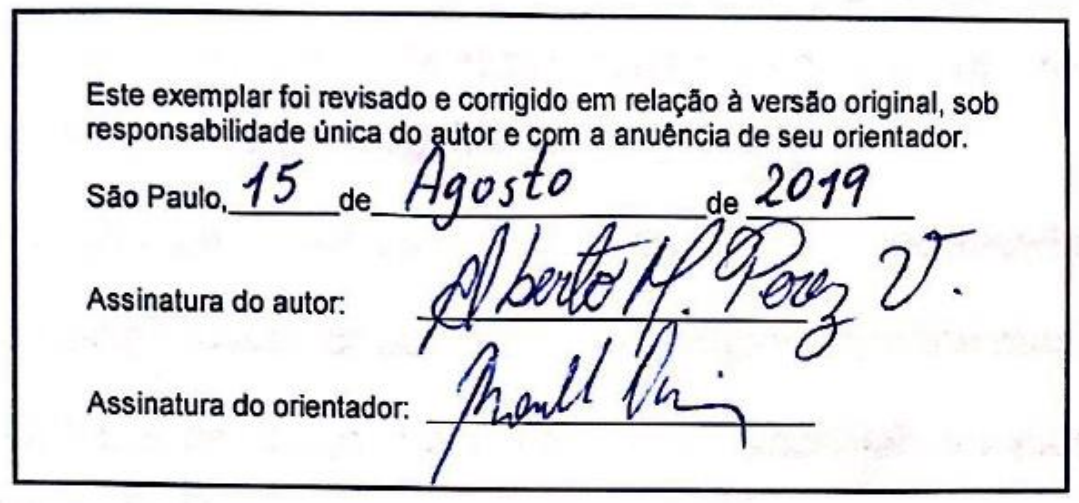

Catalogação-na-publicação

PEREZ VENERA, Alberto $M$.

ANALYSIS OF RISKS ASSOCIATED WITH EXPLORATION WELL

DRILLING IN THE BRAZILIAN EQUATORIAL MARGIN / A. M. PEREZ

VENERA - versão corr. - São Paulo, 2019.

$65 \mathrm{p}$.

Dissertação (Mestrado) - Escola Politécnica da Universidade de São Paulo. Departamento de Engenharia de Minas e Petróleo.

1.Risk Analysis 2.Drilling Hazard 3.Exploration Well 4.Brazilian Equatorial Margin I.Universidade de São Paulo. Escola Politécnica. Departamento de Engenharia de Minas e Petróleo II.t. 


\section{ACKNOWLEDGMENTS}

The author wishes to thank ANP and CAPES for doing possible this work, prof. Ronaldo and Márcio for all the patience, support and accompaniment throughout these years, prof. Carina for provide me scientific writing tools.

Prof. Cristiano, prof. Sampaio, prof. Jean for sharing his ideas and knowledge with me. Luigi Jovane and Daniel Pavani for partnering and supporting in the map elaboration. My colleagues and friends Diego, Sebastian, Joan, Jhonatan for partnership and friendship over these years.

The many people for who somehow or other helping me get here: USP Santos people, Eliana, EILE people and my roommates.

Special thanks to Olga for our long talks and laugh in the library.

Special thanks for my dear friend Rodrigo for being like a brother for me and always being there for me.

Special thanks to Luza for being such motivation for me. Thank you so much for our powerful talks and doing my heart smile.

Special thanks to my family for believing in me.

And finally, thank you so much to my mom for existing and God for giving me such opportunity. 


\begin{abstract}
Even though exploratory maritime activities in Brazil had begun in the early 1970s, the Brazilian Equatorial Margin (BEM) is still considered an exploratory frontier. Geological similarities with the Gulf of Guinea in Africa, where the Jubilee field was discovered, motivated the arrival of new international operating companies in Brazil giving to BEM a renewed commercial interest. Further tectonic, climatic and biotic evolution of this region continues being the object of several scientific studies. However, deepwater well drilling in an under-explored area is a challenging task due to all type of risks involved. A risk analysis is mandatory is to eliminate or reduce potential damage to people, environment or assets. Most of the drilling problems are derived from geological, metocean and human factors which resulted in significant delays on the drilling program or, in the worst cases, early well abandonment. The purpose of this work is to assess qualitatively the risks associated with exploratory well drilling in the Brazilian Equatorial Margin by collecting, synthesizing, and interpreting incident and occurrence data from offshore wells drilled off the coast of the state of Ceará. This research is divided into two parts. The first part includes the hazard identification based on the well folders and drilling reports of 14 exploratory wells obtained from ANP's Exploration and Production Data Base. The second part of this research is a quantitative analysis to identify the frequency and severity of risk events. The frequency was obtained from the same well folders and drilling reports used to in the first part. To identify the severity, a questionnaire survey was sent to well engineering professionals in Brazil and abroad using the social networking services available. As a result, the events of highest risk for the operation was the lost circulation. The second highest risk place is shared between pipe sticking and wellbore instability. Discussions about risk mitigation of such risks identified in this research are included.
\end{abstract}

Keywords: Risk Analysis. Drilling Hazards. Exploration Wells. Brazilian Equatorial Margin. 


\section{RESUMO}

Embora as atividades marítimas exploratórias tenham começado no início dos anos 1970, a Margem Equatorial Brasileira (BEM) ainda é considerada uma fronteira exploratória. Semelhanças geológicas com o Golfo da Guiné, na África, onde o campo do Jubileu foi descoberto, motivaram a chegada de novas empresas operadoras internacionais no Brasil, dando ao BEM um interesse comercial renovado. Além disso, a evolução tectônica, climática e biótica de esta região continua sendo o objeto de vários estudos científicos. No entanto, a perfuração de poços offshore em uma área pouco explorada é uma tarefa desafiadora devido a todos os tipos de riscos envolvidos. Uma análise de risco é obrigatória para eliminar ou reduzir possíveis danos a pessoas, ambiente ou bens. A maioria dos problemas derivam de condições geológicas, metoceânicas e fatores humanos o que resulta em atrasos significativos no programa de perfuração e, nos piores casos, abandono precoce de poço. 0 objetivo deste trabalho é avaliar qualitativamente os riscos associados com perfuração de poços exploratórios na Margem Equatorial Brasileira, através da coleta, síntese e interpretação de dados de incidentes e ocorrência de poços perfurados ao largo da costa do estado do Ceará. Esta pesquisa é dividida em duas partes. A primeira parte inclui a identificação dos riscos com base nas pastas de poços e relatórios de perfuração de 14 poços exploratórios obtidos da Base de Dados de Exploração e Produção da ANP. A segunda parte desta pesquisa é uma análise quantitativa para identificar a frequência e gravidade dos eventos de risco. A frequência foi obtida a partir das mesmas pastas de poços e relatórios de perfuração utilizados na primeira parte. Para identificar a gravidade, foi enviado um questionário para profissionais de engenharia de poços no Brasil e no exterior, utilizando os serviços de redes sociais disponíveis. Como resultado, os eventos de maior risco para a operação foram a perda de circulação. O segundo maior risco é dividido entre a prisão de coluna e a instabilidade do poço. Foram incluídas discussões sobre mitigação de risco dos riscos identificados nesta pesquisa.

Palavras-chave: Análise de risco. Riscos na Perfuração. Poços Exploratórios. Margem Equatorial brasileira. 


\section{LIST OF FIGURES}

Figure 1 - The NoRTh BRAZIL CURRENT AS REPRESENTED BY THE MARIANO GLOBAL

SURFACE VELOCITY ANALYSIS (MGSVA) ............................................. 19

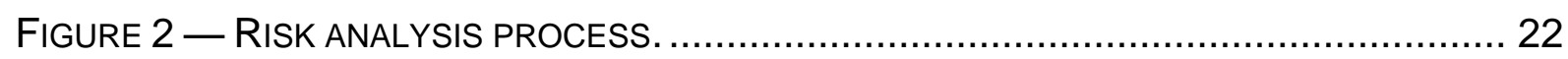

FIGURE 3 — TYPICAL EXPLORATORY WELL DESIGN. ......................................... 24

FIGURE 4 - ANP WEBMAPS HOMEPAGE. IN THE TABLE OF CONTENTS (LEFT), THE USER

MAY SELECT TYPE OF DATA THAT DESIRE VISUALIZE ON THE INTERACTIVE MAP. ......... 25

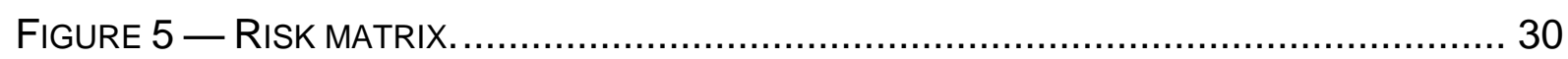

FIGURE 6 - LOCATION OF THE WELLS STUDIED ALONG THE COAST OF THE STATE OF CEARÁ, IN THE NORTHEAST OF BRAZIL. ......................................................... 32

FIGURE 7 - SONIC PROFILE INDICATING A HIGH-PRESSURE ZONE (IN RED) IN THE 1-CES-

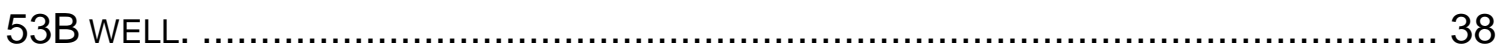

FIGURE 8 - PERCENTAGES OF OCCURRENCE OF DRILLING HAZARDS ON THE OPERATION.

FIGURE 9 - NUMBER OF CASES OF DRILLING PROBLEMS. SOURCE: AUTHOR. 54 


\section{LIST OF TABLES}

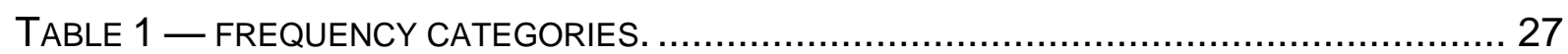

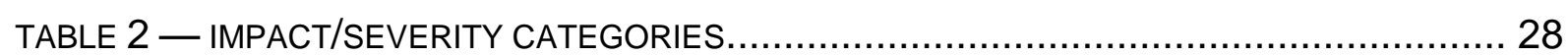

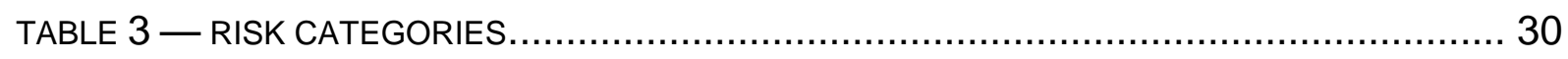

TABLE 4 — GENERAL INFORMATION OF THE 1-CES-48A WELL................................. 33

TABLE 5 — DRILLING PROBLEMS IN THE 1-CES-48A WELL..................................... 34

TABLE 6 - GENERAL INFORMATION OF THE 1-CES-50 WELL. ................................ 36

TABLE 7 — DRILLING PROBLEMS IN THE 1-CES-50 WELL...................................... 36

TABLE 8 - GENERAL INFORMATION OF THE 1-CES-53B WELL. .................................... 39

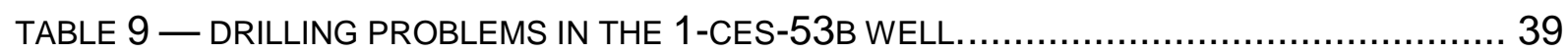

TABLE 10 — GENERAL INFORMATION OF THE 1-CES-56 WELL................................ 42

TABLE 11 — DRILLING PROBLEMS IN THE 1-CES-56 WELL.................................... 42

TABLE 12 — GENERAL INFORMATION OF THE 1-CES-111B WELL. ................................ 44

TABLE 13 — DRILLING PROBLEMS IN THE 1-CES-111B WELL................................. 44

TABLE 14 — GENERAL INFORMATION OF THE 1-CES-112 WELL................................ 46

TABLE 15 — DRILLING PROBLEMS IN THE 1-CES-112 WELL.................................. 46

TABLE 16 — GENERAL INFORMATION OF THE 1-CES-121 WELL................................ 49

TABLE 17 — DRILLING PROBLEMS IN THE 1-CES-121 WELL................................... 49

TABLE 18 — SUMMARY OF RISK EVENTS IDENTIFIED. ........................................ 51

TABLE 19 — EVENT IMPACT FROM QUESTIONNAIRE OUTCOME. ................................ 55

TABLE 20 — RISK LEVEL OF EVENTS EXAMINED. ................................................ 58 


\section{LIST OF ACRONYMS}

\begin{tabular}{|c|c|}
\hline ANP & $\begin{array}{l}\text { Brazilian National Agency of Petroleum, Natural Gas and } \\
\text { Biofuels (In Portuguese: Agência Nacional do Petróleo, Gás } \\
\text { Natural e Biocombustíveis) }\end{array}$ \\
\hline BDEP & $\begin{array}{l}\text { Exploration and Production Database (In Portuguese: Banco de } \\
\text { Dados de Exploração e Produção) }\end{array}$ \\
\hline BEM & Brazilian Equatorial Margin \\
\hline BOBT & Bit-on-Bottom Time \\
\hline $\mathrm{BOP}$ & Blowout Preventer \\
\hline CNP & National Petroleum Council \\
\hline EAD & $\begin{array}{l}\text { Data Acquisition Company (In Portuguese: Empresa de } \\
\text { Aquisição de dados) }\end{array}$ \\
\hline ECD & Equivalent Circulation Density \\
\hline IODP & Integrated Ocean Drilling Program \\
\hline MODU & Mobile Offshore Drilling Units \\
\hline NBC & North Brazil Current \\
\hline NPT & Non-Productive Time \\
\hline PCS & Pressure Core Sampler \\
\hline PHA & Preliminary Hazard Analysis \\
\hline PWD & Pressure-While-Drilling \\
\hline QRA & Quantitative Risk Analysis \\
\hline SJA & Safe Job Analysis \\
\hline VIV & Vortex-Induced Vibration \\
\hline
\end{tabular}




\section{TABLE OF CONTENTS}

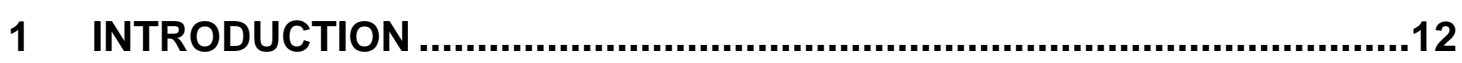

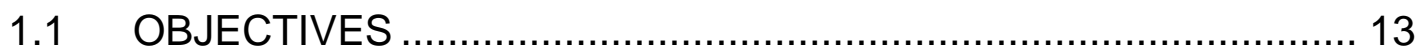

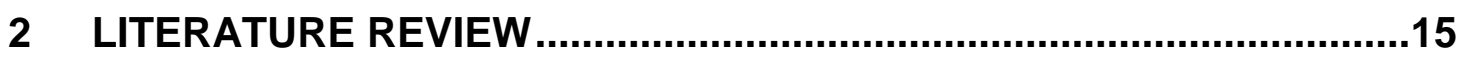

2.1 BRAZILIAN EQUATORIAL MARGIN (BEM) …........................... 15

2.2 DEEPWATER DRILLING CHALLENGES .................................... 17

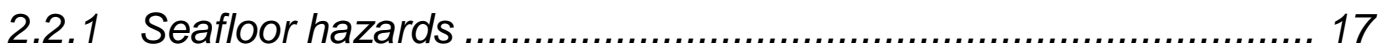

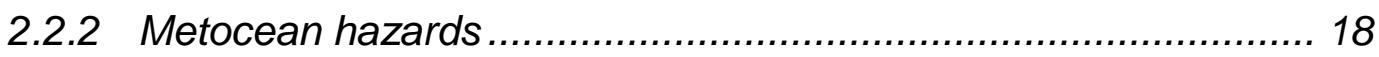

2.2.3 Subsurface geologic hazards ................................................. 19

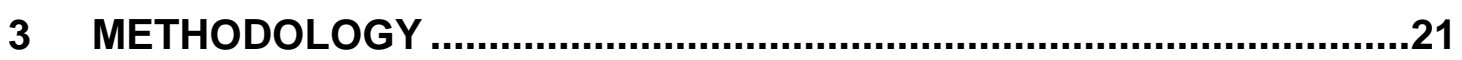

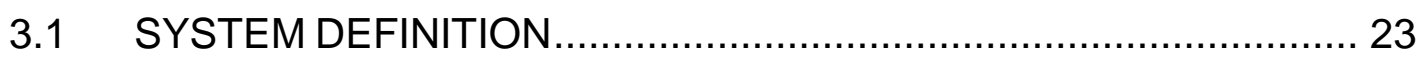

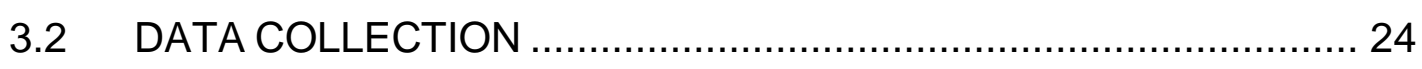

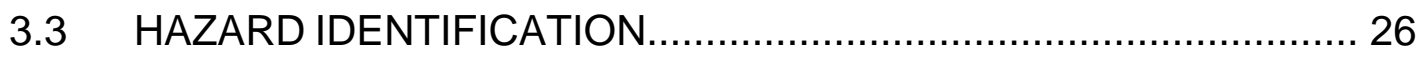

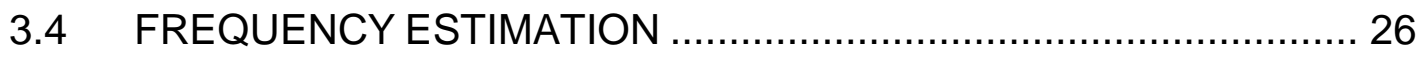

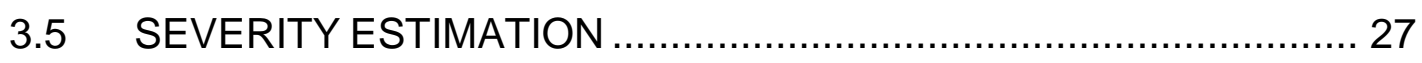

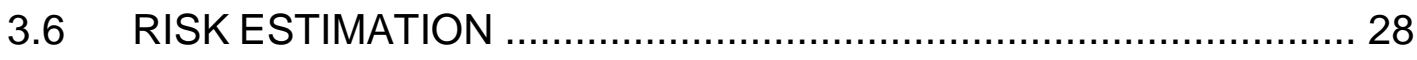

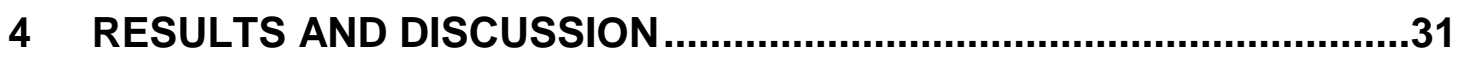

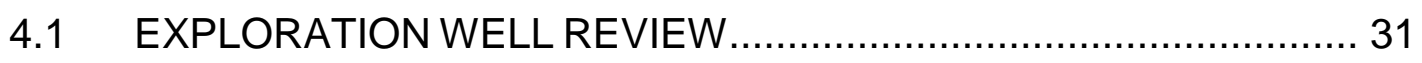

4.1.1 1-CES-48A well ................................................................ 32

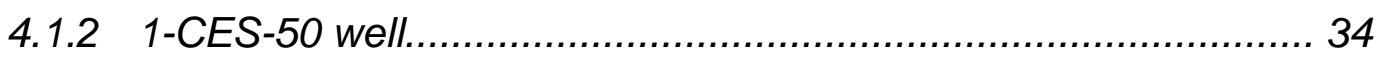

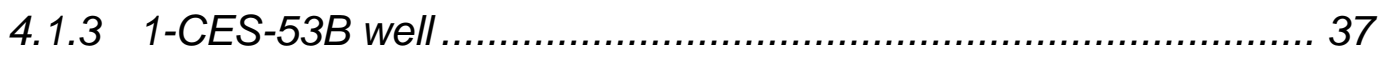

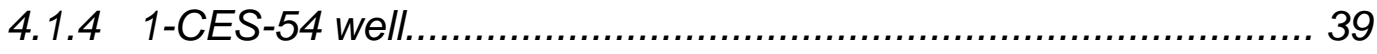

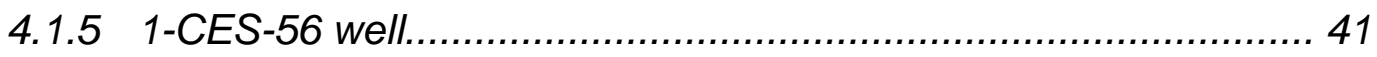

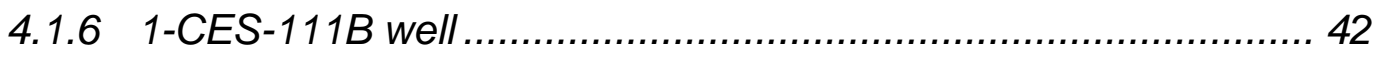

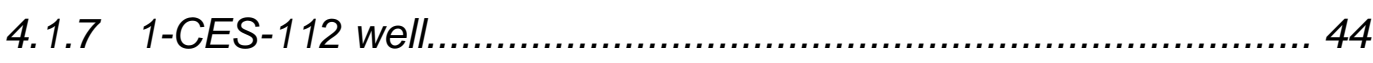

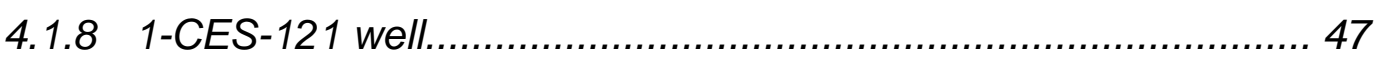

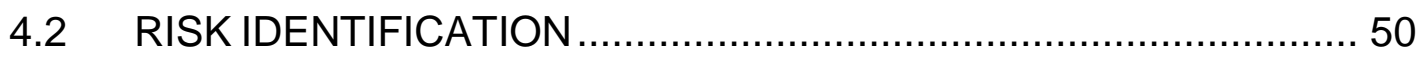

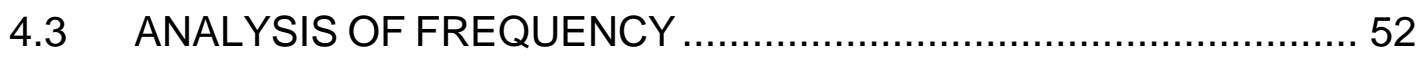




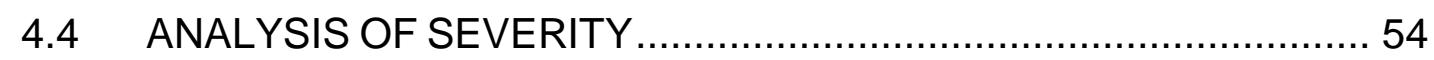

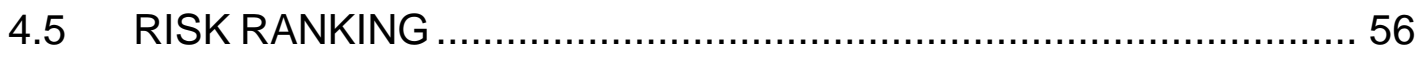

5 CONCLUSION ...........................................................................60

REFERENCES.......................................................64 


\section{INTRODUCTION}

The Brazilian Equatorial margin (BEM) represents a promising potential area. Recent deepwater oil discoveries from Zaedyus well in offshore French Guiana and from Ceará Basin Pecem well off the northeast coast of Brazil suggest existence of petroleum system similarities with the West African margin, where world-class Jubilee field was discovered (MELLO et al., 2013). These initial outcomes are encouraging and have attracted strong private investments and scientific studies, indicating an important move by the oil companies and researchers to further explore the BEM basins. Today, more than ten operating companies have concession contracts of BEM exploratory blocks granted by the Brazilian Agency of Petroleum, Natural Gas and Biofuels (ANP) (AVILA, 2018). In addition, four scientific drilling proposals (IODP Proposal 945) (IODP Proposal 910) (IODP Proposal 859) (IODP Proposal 864) have been submitted to Integrated Ocean Drilling Program (IODP) in order to gather valuable information for understanding the tectonic, climatic and biotic evolution of this region (INTEGRATED OCEAN DRILLING PROGRAM, 2019).

However, deepwater drilling in the BEM introduces multiple additional risks and complex challenges compared to other maritime regions and conventional drilling. For instance, the BEM is a relatively unexplored area, specifically in deep and ultra-deep water, where only 3 wells have been drilled. Little information about the BEM petroleum systems is available so that hydrocarbon generation potential in each of the basins is not yet proven (FAVERA et al., 2013). Efforts have been made to integrate different exploration technologies in order to identify potential prospects in Potiguar and Ceará basins and to reduce exploratory risk (BENDER et al., 2010). Respecting the risks at the operation, the $B E M$ is regarded as a high current environment since it is dominated by the North Brazil Current (NBC). Surface and subsurface currents driven from NBC may create rig positioning and riser management problems whose associated costs increase significantly with water depths. Another environmental hazards include but are not limited to: the presence of gas hydrate zones at shallow depths which are typically associated with over-pressured formations (KIRAN et al., 2017), weak surface formations with poor support capability causing well spudding problems (BARCELOS; AWAD; ASSUNCAO, 1994), narrow window between pore pressure and fracture 
pressure to operate (BHANDARI et al., 2015). These factors may cause potential issues such as severe loss of drilling fluid, sticking and torqueing pipes, high-pressure fluid influx into the well, buckling and failure of the casing, wellbore instabilities, and incentive for kick and blowout.

Since there are many risks involved, performing a qualitative risk analysis is mandatory in the entire risk management process. The intention here is to collect, identify and prioritized, from different data sources, the expected characteristics and problems to be encountered in drilling the prospect well so that probabilistic risk studies can be carried out. However, planning properly a well in unknown environments is not a simple task. Most offset information is confidential and becomes public domain a short time after the well is completed or when the operator has no further leasing interest in the area. Thus, this study provides significative insights that help to develop the projected drilling conditions. Instable-formation derived problems, for instance, an important concern in the study area given to premature abandonment and sidetrack cases observed.

\subsection{OBJECTIVES}

This work is aimed at conducting a qualitative risk assessment for exploration drilling operations in the Brazilian Equatorial Margin following the international safety standards NORSOK Z-013 and API-RP 580. The purpose of conducting this analysis is to establish a clear risk picture based on the drilling reports of the offset well and the judgment of technical experts and to provide the basis for further risk studies and formulation of risk-reducing measures.

As an initial part of the process, the occurrences and unwanted events during the operation will be identified by reviewing the well folders. Each well folder includes relevant files such as drilling reports, composite log and well log data that will be subsequently utilized to analyze causes of identified events.

Once causes and consequences of each event are defined, the next objective is to construct a risk matrix, where consequence severity, occurrence likelihood, and risk categories will be established based on case studies found on literature. 
As a final step, each hazardous event will be ranked by using the risk matrix diagram and risk-reducing measures, suggestions, and recommendations to optimize the drilling operation will be provided according to experts' contributions. 


\section{LITERATURE REVIEW}

In this section is presented relevant aspects of Brazilian Equatorial Margin background and geological framework found into the literature. Further, a review of common problems during the drilling operation is also included.

\subsection{BRAZILIAN EQUATORIAL MARGIN (BEM)}

The BEM is a passive and stable continental margin at equatorial latitudes, which originated during the final opening of the Atlantic Ocean in the mid-Cretaceous. The peculiarity of this margin is maintained its passive geological regime about the same latitude from its formation to the present. Such conditions are unique and offer great potential for deposition and preservation of intertropical environments sediments. In addition, the identification of trapped oil and successful discoveries off the coast of Nigeria, Ghana and Equatorial Guinea at the same latitude have confirmed the prospective potential of the region (WERTHEIM, 2011).

The Ceara and Potiguar basins, where the wells examined are located, are part of the five offshore sedimentary basins bordering the BEM, which include, from NW to SE: Foz do Amazonas, Pará-Maranhão, Barreirinhas, Ceará, and Potiguar, which are roughly limited by the Atlantic Equatorial fracture zones.. The origin of the Ceará Basin is linked to the process of rupture of the paleocontact Gondwana, during the Eocretáceo (Aptian), at the opening of the Equatorial Atlantic. This complex geodynamic scenario was responsible for large variations in the geometry, in the structural collection and in the sedimentary filling of the sedimentary basins of the Brazilian equatorial margin. Specifically, in Ceará, this event favored internal tectonostratigraphic differentiation, strongly influencing its compartmentalization in the Piauí-Camocim, Acaraú, Icaraí and Mundaú sub-basins, which present slightly different depositional and deformation histories (BASTOS, 2017).

Hydrocarbon exploration in the BEM began in 1949, with surface mapping and gravimetric and magnetometric surveys in the Potiguar basin conducted by the National Petroleum Council (CNP). Exploration activities intensified in the 1970s in the context of the first oil crisis. New seismic surveys, both marine (the majority in shallow 
water) and terrestrial, led to the discovery of the Ubarana in the Potiguar basin (1973), Pirapema in the Foz do Amazonas basin (1976), and Xareu in the Ceara basin (1977) (BASTOS, 2017; BATISTA, 2017).

The period between 1980 and 1990 corresponds to the phase of greater investment in the Region. In the Potiguar basin, 675 exploratory wells were drilled, which represent approximately $52 \%$ of the total drilled in the basin to date.

After the creation of the ANP in 1997 (Law 9.478 / 97), non-exclusive seismic surveys were carried out by data acquisition companies (EADs) in the maritime portion. Blocks of the Potiguar Basin were included in all the bidding rounds, except for the Round 8 and Round 12. During this period, some discoveries were made, as well as the incorporation of small reserves by Petrobras.

By the end of the 1990s, the exploration activities focused on the deepwater region. However, the constant mechanical problems had resulted in several well abandonments that have turned into a serious challenge for the operators. The new drilling campaigns were the result of the bidding rounds carried out by the ANP, which allowed the participation of private sector companies. The first deepwater discovery of hydrocarbons was found in turbidite deposits of the Paracuru formation (Ceará basin) through the 1-CES-158-CE well owned by Petrobras, in consortium with BP Energy do Brasil. To date, less than 40 wells have been drilled in deep waters. 


\subsection{DEEPWATER DRILLING CHALLENGES}

Deepwater drilling is one of the high-risk operations in the oil and gas industry due to uncertainties and hash operation conditions. Then, some difficulties to be considered for the companies willing to operate in this region are discussed below:

\subsubsection{SEAFLOOR HAZARDS}

Seafloor conditions are important issue for the drill site selection. This type of hazard is related to slope stability and seafloor variability, and its analysis is fundamental avoid spud-in and wellhead leveling problems. Seafloor hazards include fault escarpments, unstable slopes, mud-flow gullies and lobes, slumps, diapirs, gas vents, collapse features, sand waves, chemosynthetic communities, hydrate mounds, mud lumps, mud volcanoes, rock outcrops, pinnacles, and reefs (BRUCE; SHIPP, 2003).

Hydrites (clathrates), for example, are normally found in continental margin with high sedimentation rates, assuring a quick burial and preservation of existing organic material. Geophysical studies on the Brazilian continental margin have reveled gas hydrates occurrences from Foz do Amazonas, in the equatorial region (SAD et al., 1998), to Pelotas basin, in the south (FONTANA; MUSSUMECI, 1994). High sedimentation rate in West BEM, for example, results from the presence of large rivers and the accumulation of terrigenous sediments transported by the North Brazil Current (NBC) from other areas (ALVES, 2018). The occurrences were first detected through bottom-simulating reflectors (BSR) and has recently been proven by seafloor sampling of gas vents, observed as water column acoustic anomalies rising from seafloor depressions (pockmarks) and/or mounds (KETZER et al., 2019). In other regions such as Campos, Espirito Santo and Cumuruxatiba basins, where diapirs are common, gas hydrates are likely to occur in association with localized exudations, such as those found in the Gulf of Mexico and the Niger Delta (HOVLAND et al., 1997).

Hydrates and authigenic carbonate pavements may form an effective pressure seal and free gas may accumulate under the seal. Pressure core sampler (PCS) data have indicated that the biogenic gas pressure can be 350 psi above seawater 
hydrostatic pressure (i.e., it is overpressured) at $450 \mathrm{~m}$ (GRABER, 2007). The major preoccupation here would be the high-pressure gas flow into the wellbore environment. Uncontrolled, or improperly controlled, fluid influx is a significant risk with the most severe consequences such as blowout.

\subsubsection{METOCEAN HAZARDS}

Oceanic currents are an important issue for risk analysis of deepwater drilling operations because can cause drift-off of floating MODUs and to produce vortexinduced vibrations (VIV) that reduce risers' fatigue life. These vibrations occur when the risers or any bluff body is exposed to a current, which produce alternating vortices shedding in a frequency at, or near, a structural natural frequency of the riser's structure. As they are shed, the vortices cause alternating forces on the body both directions, transverse and parallel to the flow. The frequency at which this vortex shedding depends on the diameter of the body and the velocity of the flow (GARDNER; COLE, 1982).

Deepwater risers are especially susceptible to VIV because i) currents are typically higher in deepwater areas than in shallower areas; ii) the increased length of the riser lowers its natural frequency thereby lowering the magnitude of current required to excite VIV, and iii) deepwater platforms are floating platforms so that there are no structures adjacent to the riser to which it could be clamped (ALLEN, 1998).

In the BEM, the dominant surface current is the North Brazil Current (CNB) originated from the northern bifurcation of the South Equatorial Current (SEC) coming as it approaches the continental shelf off of Cabo de Sao Roque, Brazil (SILVEIRA et al., 2000) (Figure 1). During the last 30 years, this strong current has led to failures in risers, subsea BOPs and wellbore integrity as MODU is pushed away from the location. The severity of this damages is defined from the current intensity. According to GARDNER; COLE (1982), the North Current magnitude may be up to more than 4 knots in surface to one knot on the seafloor being capable of causing vortex pulsing along a pipe over a range of frequencies, which is difficult the VIV prediction of the vibration amplitude and reliable fatigue analysis. 
Figure 1 - The North Brazil current as represented by the Mariano Global Surface Velocity Analysis (MGSVA)

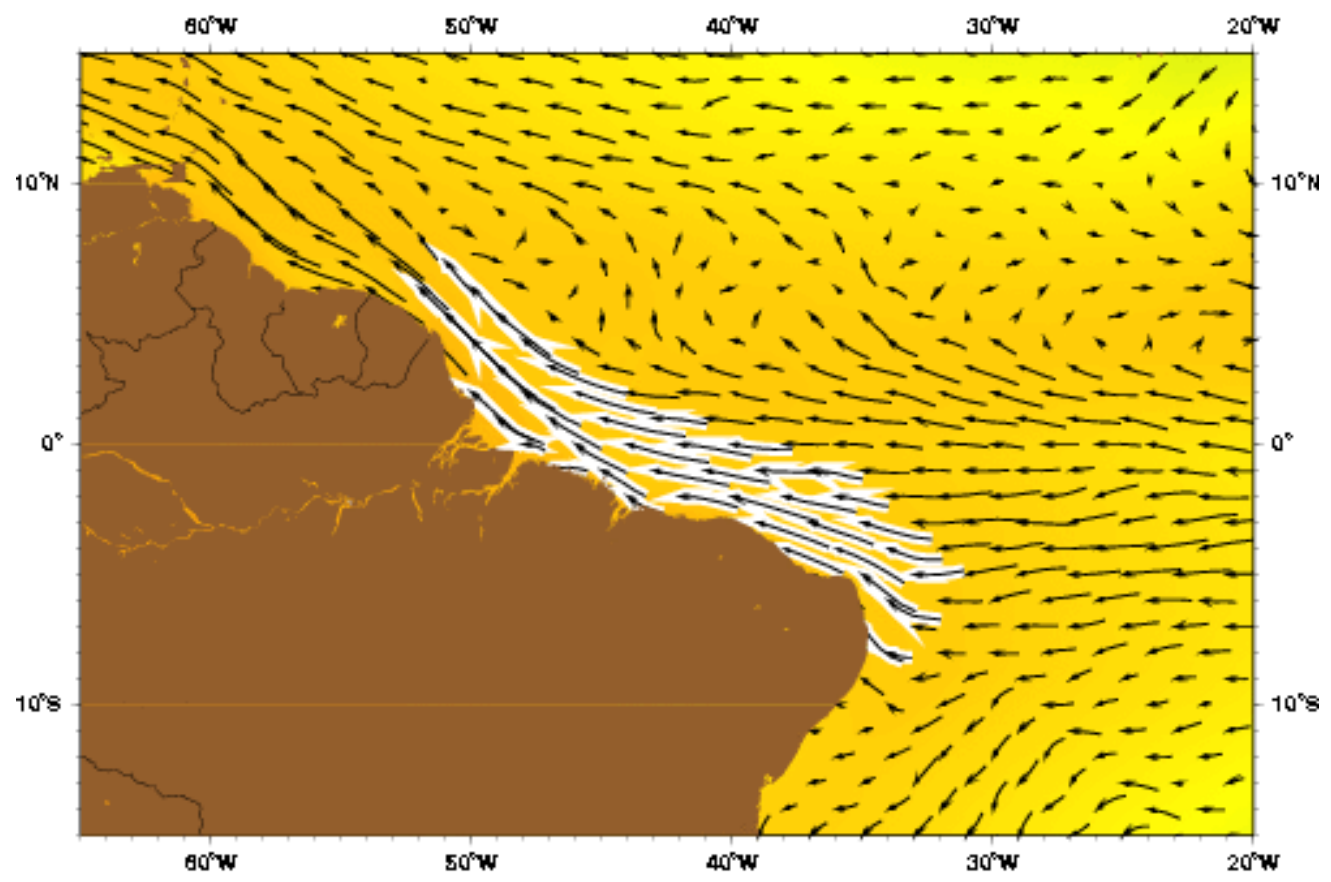

Source: Bischof, Mariano, and Ryan (2003)

\subsubsection{SUBSURFACE GEOLOGIC HAZARDS}

The thief zones, particularly the low fracture pressure zones, can greatly increase drilling non-productive times and cause serious lost circulation events that, in the worst case, would lead to sidetracking or abandonment of the well. According to LAVROV (2016), the lost circulation was responsible for more than $10 \%$ of the nonproductive time during drilling operations in the Gulf of Mexico between 1993 and 2003. The ability to control effectively losses means a great impact on the project economics because of the costs of drilling fluid represent between $25-40 \%$ of total drilling expenditure.

In addition to the direct economic impact, lost circulation may cause additional drilling problems, the insufficient fluid in the well may impair cuttings transport to the surface, which may lead to poor hole cleaning, especially in deviated and horizontal wells. The poor hole cleaning may eventually result in bridges and stuck pipe. 
The invasion of the drilling fluid into the formation in the pay zone increases formation damage as the pores and fractures in the reservoir rock become plugged with particles present in the drilling mud (barite, bentonite, cuttings, solids used as lost circulation material, etc.). Thus, the formation damage created by lost circulation needs to be mitigated before production starts, which leads to additional costs.

The most severe cases of lost circulation may lead to well control problems. The reduced wellbore pressures as a result of excessive losses of fluid are insufficient to keep the well over-balanced. Thus, the undesired avoid influx of formation fluids into the wellbore or even borehole collapse shall occur.

The low fracture pressure zones not only represent a risk during the drilling, but also a challenge in the planning phase, especially of wildcat wells where little or no known geological data are available. Low-pressure gradient values result in a narrow drilling margin which can provoke new requirements of time, casing, mud weight, and cement - and increase substantially to the overall cost of a well. The typical challenges include a remarkable restriction in the maximum allowable open hole drilled depth, the requirement of setting multiple casing strings to reached target depth resulting in loss of hole diameter, rigorous ECD control (ROCHA; AZEVEDO, 2007).

The mechanisms responsible by low fracture pressure gradient generation may vary according to the environment: high-temperature and high-pressure formations (HTPT), depleted or deepwater reservoirs. In offshore wells, one of the main causes of a narrow drilling window. As water depth increases, the hydrostatic pressure exerted by the seawater column essentially reduces the pressure that would be exerted by the overburden, resulting in a reduced fracture pressure gradient. In addition, poorly consolidated, structurally weak, low compacted sediments commonly found in the shallower portion of the subsurface can reduce even further the fracture gradient and therefore mud weight window (ERIVWO; ADELEYE, 2012; ROCHA et al., 2004). 


\section{METHODOLOGY}

Before presenting the research procedure followed, it is important set the differences between the terms risk and hazard which are commonly used interchangeably in the literature. According to ISO (2009), risk is defined as the "effect of uncertainty on objectives". In this definition, uncertainties include events (which may or may not happen) whose impact may be both positive and negative. Objectives may involve different aspects (such as financial, health and safety and environmental goals) and levels (such as strategic, organization-wide, project, product, and process). On other hand, hazards are sources of risk, tangible or no tangible elements which alone or in combination has the potential to give rise to risk. Thus, in a drilling safety context, drilling risks is related to impact of encountering unanticipated overpressure zones, mudslides, adverse weather conditions, mud volcano eruptions, mobile formations narrowing the hole, contracting untrained rig personnel, etc. These events, physical features or activities may be addressed as drilling hazards.

Qualitative risk analysis is a method for estimating the level of risk based on the descriptive information from engineering judgment and experience. Usually, it is used in a system with a great lack of comprehensive industry information for accident scenarios. The operators in the North Sea, for example, maintain accurate records and share the data regarding the occurrences in the drilling operations (OREDA, 2015). However, the major operating company in Brazil does not share the data regarding the occurrences during the deepwater drilling.

Because the shared data are not always accurate, the quality of a quantitative risk analysis depends heavily on the of the background and expertise of the risk analysts and team members. Inputs are often given in data ranges instead of discrete values. Results are typically given in qualitative terms such as high, medium, and low, although numerical values may also be associated with these categories. The value of this type of analysis is that it enables completion of a risk assessment in the absence of detailed quantitative data (API, 2009). 
Although a qualitative type of risk analysis is less precise than a quantitative one, it is effective in helping the screening and selection of the well site, communicating the project aspects to the public, and aiding the regulators in licensing and permitting at the initial stages of the project. After more detailed site characterization and modeling efforts, quantitative risk analysis may be performed to estimate the likelihood of human health and environmental risks. Furthermore, stakeholders such as regulators and insurers may require risk analysis to support incentives, such as loan guarantees to large projects. A successful risk analysis will always be linked to monitoring and modeling plans for a given drilling site (CHAE; LEE, 2015). Some examples of qualitative risk analyses are Safe Job Analysis (SJA), Preliminary Hazard Analysis (PHA), coarse risk analysis with risk matrix presentation, 'Driller's HAZOP' and simple comparative studies.

NORSOK (2001) established general requirements for planning and executing risk studies, placing the main emphasis on quantitative risk analysis (QRA). Thus, no specific requirements are formulated for a qualitative approach. However, in order to provide a greater level of detail, this work will comprise the steps as shown in Figure 2.

Figure 2 - Risk analysis process.

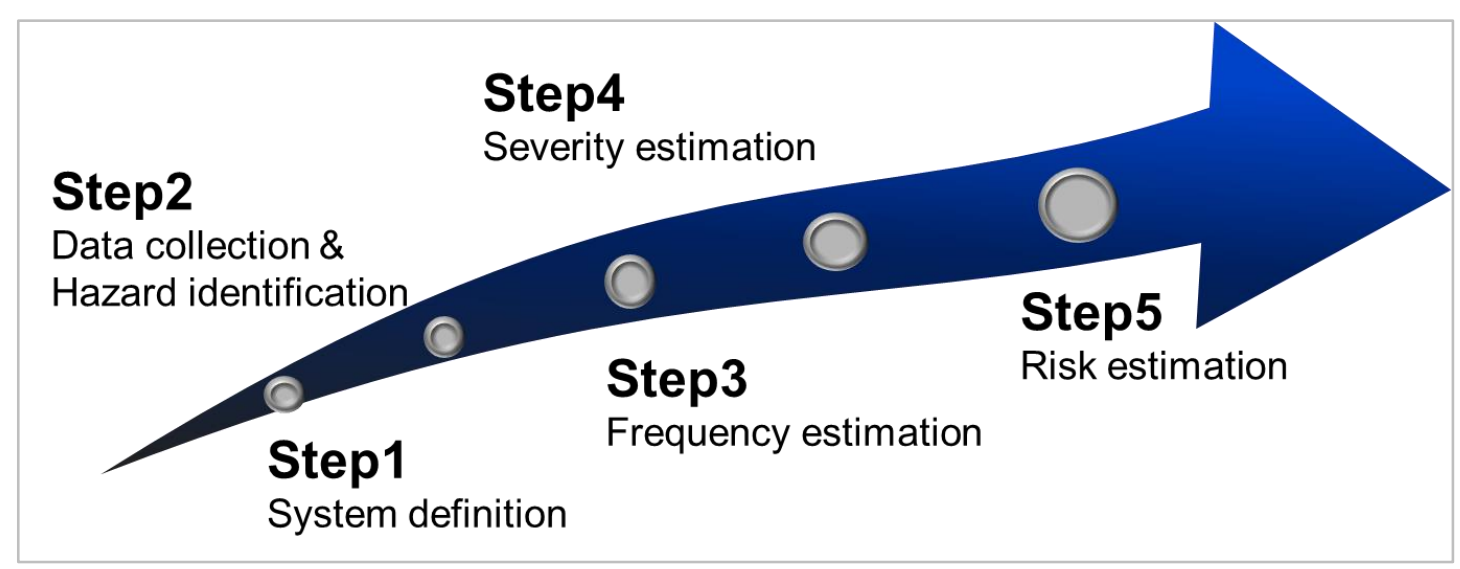

Source: NTS, 2001. 


\subsection{SYSTEM DEFINITION}

The study object or system of this work is exploration wells drilled in the BEM that may be used as correlation wells for IODP drilling proposals. Thus, activities and phases of the construction process, as seen in Figure 3, were examined. The wells were addressed as technical systems where personnel and organizational factors were not considered but the hardware-environment interface. This interface concerns the relationship between the physical, non-human and environment elements of the system. Physical elements comprise equipment. Non-human or operational elements involved work procedures and practices necessary for the drilling process. Environmental elements involve the geological and metocean conditions of the well site. The latter being a variable of interest in this study.

Figure 3 shows a typical exploratory well configuration with and a description of its construction phases is presented below. For the purposes of this work, the first and second drilling phases were analyzed as a single drilling phase due to the similarity in the nature of the problems.

Phase I and II. Includes the installation of conductor and surface casing pipes which typically possessing an outside diameter of 30 and $20 \mathrm{in}$. respectively. In this phase hazards related to vessel positioning, spudding and drilling operations can be found. Hence, the main propose of these first casing strings is to prevent poorly consolidated seafloor sediments and weak formations from collapsing into the hole and isolate shallow gas and shallow water zones. It also provides a point for the installation of a blowout preventer (BOP) or another type of diverter system.

Phase III. A $13_{3 / 8}$-in casing string is often set in the transition zone from normal to abnormal pressure, before higher mud weights are used. It allows control of the well in case of subsurface pressure higher than the mud weight and inflow of formation fluids; this is especially hazardous when the fluids contain hydrogen sulfide (sour gas). The propose of this casing string is to protect the hole from possible problem zones such as unstable hole sections, lost-circulation zones, low-pressure zones, production zones. Intermediary logging runs are usually done in this phase. 
Phase IV. A 95/8-in casing is usually set in the last cased section of the well. The intention here is to provide protection against abnormally pressurized zones, unstable formations, sour gas influx, among other hazards may be found during the drilling operation.

Phase V. The last section of the well is an open hole completion of $8 \frac{1 / 2}{2}$ in where hazards associated with logging and drilling operations may appear.

Figure 3-Typical exploratory well design.

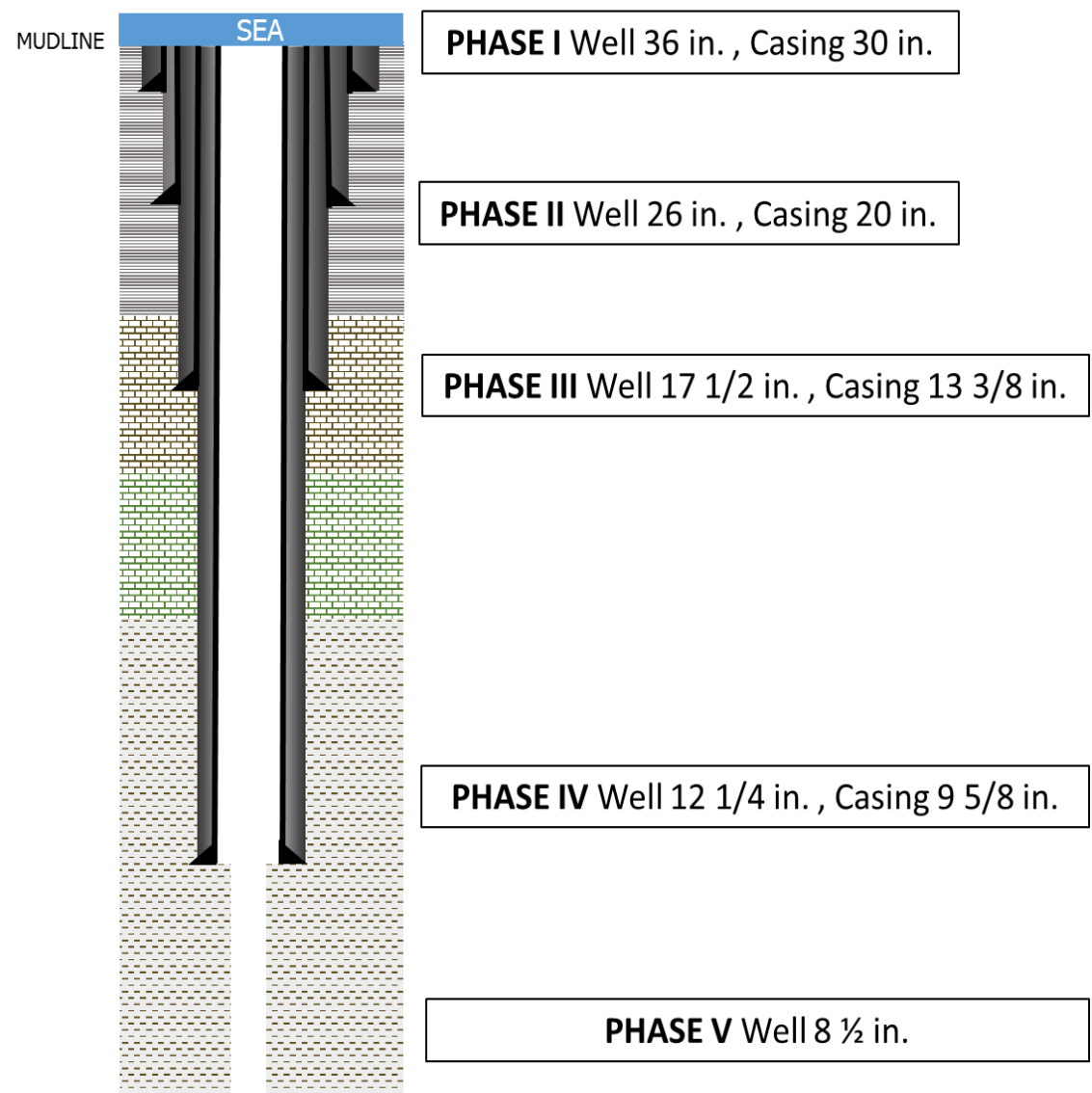

Source: Author

\subsection{DATA COLLECTION}

The wells of study were selected by using ANP WebMaps system, an interactive map with a vast collection of technical data generated in oil exploration activities throughout 
Brazil. The criteria used were the proximity of the well to drilling sites established in one of the IODP proposal. As a second criteria, availability of detailed well folders where occurrences during the drilling process were described. Figure 4 shows WebMaps homepage where, after selecting the exploration well option in the table of contents (left), it is possible to visualize the existing wells in a specific area. Once selected the wells of interest, the data were requesting to ANP BDEP (Exploration and Production Database) which made four DVDs available with following files:

Figure 4-ANP WebMaps homepage. In the table of contents (left), the user may select type of data that desire visualize on the interactive map.

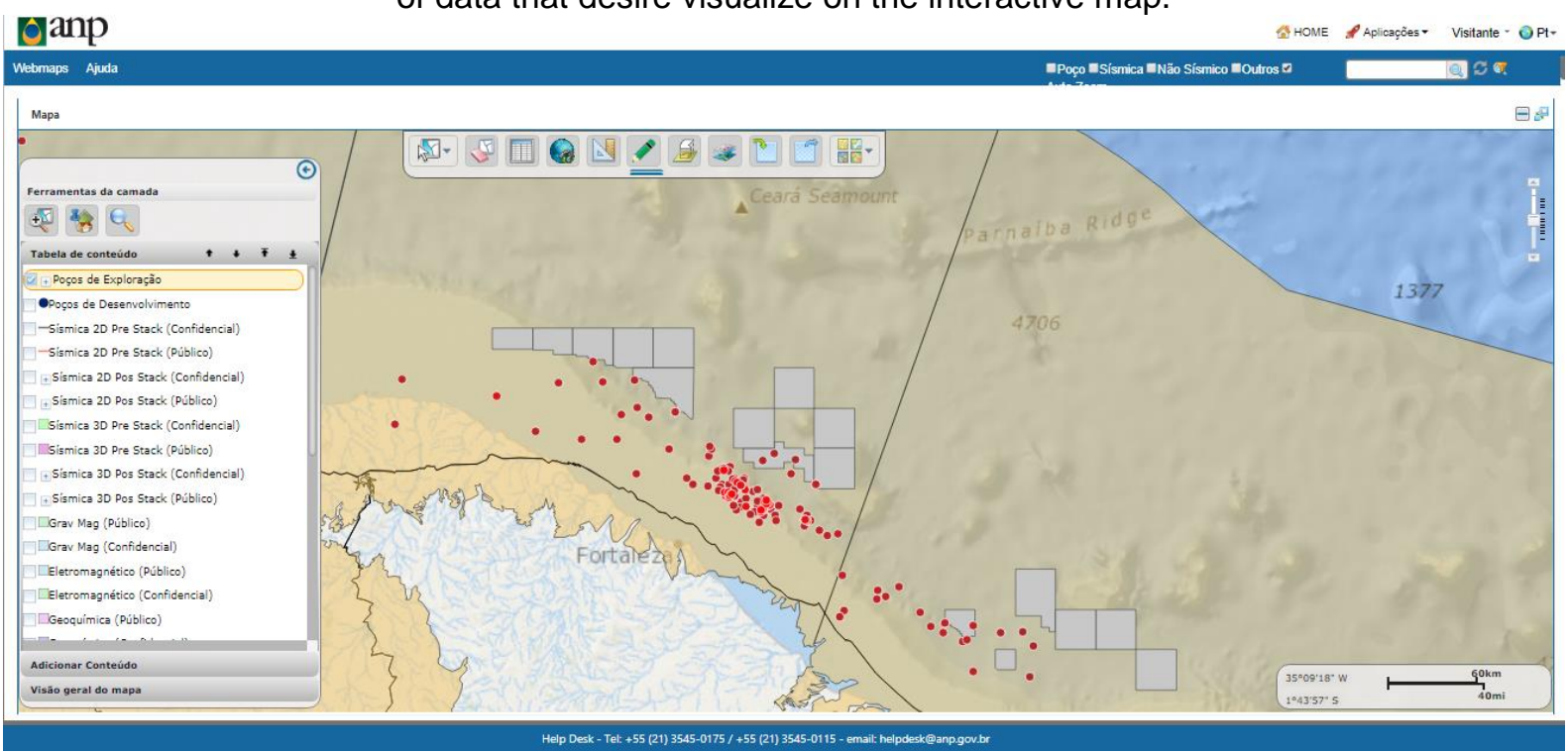

Source: ANP WebMaps homepage screen capture.

Well Folder (PP). Compilation of data and documents generated during the location, design, drilling, testing (including the acquisition of samples and data) and completion of a well (including operations such as re-entry and interventions as well as any data generated as a result thereof, sent to the ANP by the company that operates the contracted area. Although all the wells having well folders, only 8 contained the documents necessary to identify the hazards involved in the drilling operation so that uniquely these wells were considered in this work. The PP comprised Description of Drill Cuttings, Daily Monitoring Sheet of the well, Geological Reports of the well, Special Operation Registers, Daily Monitoring of Drilling Fluid, Geochemist logs, Logging Reports, Efficiency Bulletins of the drillship, Cementation Reports. 
Composite Log. A single log created by splicing together two or more logs presenting information about penetrated lithologic column and other data acquired in well drilling. It has three parts: header, main body, and baseboard. The latter part often provides information on conducting cable or pipe training tests.

Digital Logs. They are records of the physical properties of the rocks, represented graphically by curves in the formats las, lis or dlis.

\subsection{HAZARD IDENTIFICATION}

Hazard identification begun with detailed and systematic revision of all data collected in the previous step. During the process, sections with relevant information were highlighted to further establish possible associations. In the most antiques files, understanding handwritten or typewritten fragments represented a challenge.

Environmental- related events leading to non-productive times and putting the operation at risk were considered as hazards. Meanwhile, problems derived from human, organizational or equipment factors were not examined. In addition to the identification, the purpose here was full characterization of the hazards indicating its location in the well, causes or possible cause if these were not clear and the geological units involved.

\subsection{FREQUENCY ESTIMATION}

Frequency estimation is based on the descriptions of occurrences related in each drilling phase in the eight drilling reports available. Some reports include time analysis of various tasks during the drilling operation (fishing \& stuck pipe, logging, abandonment, sidetracking, casing setting, etc.) where the times are classified into Productive Time or bit-on-bottom time (BOBT), Flat Time and Lost Time. The BOBT refers to the total time the drill bit takes to drill the borehole such as drilling, spuddingin, and coring. Flat time is the time needed for constructing the well not including the BOBT (BHA handling, tripping, running casing, BOP work, drilling connections, etc.). Non-productive time (NPT) includes unplanned events like hole problems (drilling 
hazards studied), tool failures, unexpected environmental conditions etc. that arise during the drilling operation (AMORIM JUNIOR, 2008; MANDAVA; LOCKRIDGE, 2017).

The mentioned frequencies were estimated using the following equation:

$$
\text { FREQUENCY OF A EVENT (\%) }=\frac{\text { Total of an event's occurrences }}{\text { Total of drilling phases examined }}
$$

Where occurrence is defined as the number of times per drilling phase the event occurs in a well. Obtaining the value of frequency, the risk event can be classified within the six categories of frequency shown in Table 1.

Table 1 - Frequency categories.

\begin{tabular}{cccc}
\hline $\begin{array}{c}\text { Frequency } \\
\text { Factor }\end{array}$ & Category & $\begin{array}{c}\text { Quantitative } \\
\text { Range }\end{array}$ & Description \\
6 & Likely & $>40 \%$ & Likely to occur in several phases \\
5 & Occasional & $20-40 \%$ & Expected to occur at least one phase \\
4 & seldom & $10-20 \%$ & Occurrence considered rare \\
3 & Unlikely & $5-10 \%$ & Not expected nor anticipated to occur \\
2 & Remote & $<5 \%$ & Virtually improbable \\
1 & Rare & $<1 \%$ & Virtually unrealistic \\
\hline
\end{tabular}

Source: Author

\subsection{SEVERITY ESTIMATION}

In order to determinate the magnitude of loss resulting from risk events identified, a comparative questionnaire survey was prepared with six qualitative answer choices per question as showing below:

Based on your experience in the field, how severe is the impact of risk event "Loss of Circulation" on an offshore drilling operation?
a) Incidental
b) Minor 
c) Moderate

d) Major

e) Severe

f) Catastrophic

Experts having a different level of experience with offshore drilling projects are invited to answer the questionnaire through SPE Connect ${ }^{3}$ platform and Linkedln by choosing one option as their choice for each question. Their responses are later converted into quantitative data by using the equivalences shown in Table 2.

Table 2 - Impact/Severity categories.

\begin{tabular}{ccc}
\hline Impact Factor & Category & Description \\
6 & Catastrophic & Loss of the rig \\
5 & Severe & Loss of the well \\
4 & Major & Loss of more than one section \\
3 & Moderate & Loss of hole Section \\
2 & Minor & Day lost \\
1 & Incidental & Half day lost \\
\hline
\end{tabular}

Source: Author.

Based on the experts' judgments and their subsequent conversion to quantitative values, relative severity measures are estimated, and a risk matrix can be built.

\subsection{RISK ESTIMATION}

The intention here is to calculate the risk level of each hazardous event using the risk matrix. This tool allows ranking the events according to their significance, to screen out insignificant ones and to evaluate risk reduction measures where necessary. Based

\footnotetext{
${ }^{3}$ SPE Connect is a virtual platform to communicate, collaborate, and connect with fellow SPE members and Industry leaders from around the world managed by Society of Petroleum Engineers (SPE). For more information, please access https://connect.spe.org
} 
on this, three actions may be carried out to manage the risk: accept, mitigate or avoid. Accepting a risk means that the frequency and severity of the risk event happening ranks so low that it is an acceptable risk to undertake. This likelihood is commonly referred to as "as low as reasonably practical" (ALARP).

Mitigating means that the risk, as currently understood, is not acceptable and requires new or additional intervention. These new mitigations can come in the form of best practices, policies, procedures, techniques, and technologies that better manage the risk.

Avoiding usually requires revising the well design or mitigant in place or eliminating a step or task. Using a risk matrix as guidance enables to select any action that it determines to be reasonable and appropriate for the operation. A matrix provides a vehicle for documenting and organizing what is important to better understand the risk profiles of the operations and manage accordingly. Decisions are guided by company policies, rules or regulations, as well as those of the relevant regulatory authorities (PRITCHARD et al., 2010).

There are no accepted standards related to the size of the matrix, the labeling of the axes, and so on. In most risk matrices, the frequency and the severity are divided into three to six categories, with the frequency on the horizontal axis and the severity on the vertical axis. In the risk matrix illustrated in Figure 5, six categories are used for both the frequency and the severity. Each cell and its assigned value correspond to a specific combination of frequency and severity resulting from the application of the equation (2). The categories are either quantitatively or qualitatively expressed, and only consequences to the operation are considered. Risk categories from frequency and severity analysis are discussed in Table 3. 
Figure 5 - Risk matrix.

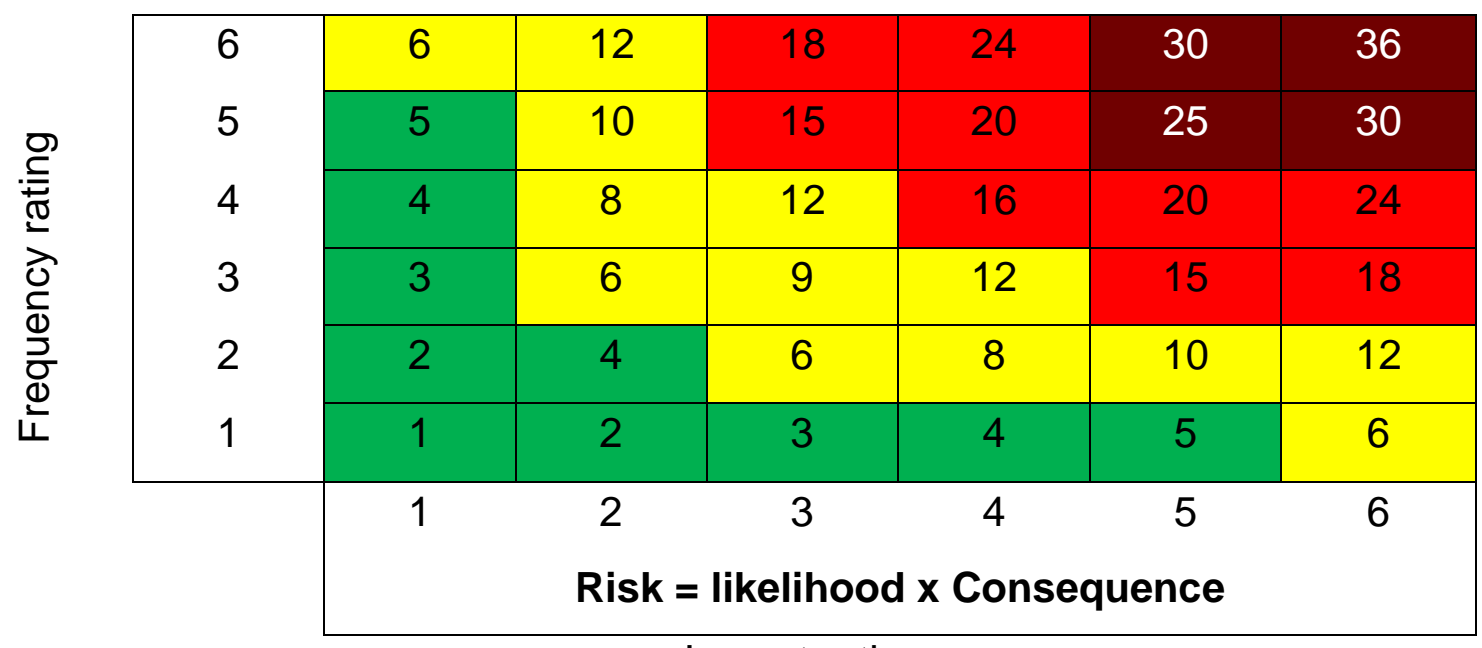

Impact rating

Source: Adapted from Dethlefs \& Chastain, 2012.

Table 3 - Risk categories.

\begin{tabular}{|c|c|c|}
\hline $\begin{array}{l}\text { IV } \\
25-36\end{array}$ & High & $\begin{array}{l}\text { High Risk. Manage the risk utilizing preventing } \\
\text { and/or mitigation with the highest priority. Promote } \\
\text { issue to appropriate management level with } \\
\text { commensurate risk assessment detail. }\end{array}$ \\
\hline $\begin{array}{l}\text { III } \\
15-24\end{array}$ & Significant & $\begin{array}{l}\text { Significant Risk. Manage the risk utilizing } \\
\text { preventing and/or mitigation with priority. Promote } \\
\text { issue to appropriate management level with } \\
\text { commensurate risk assessment detail. }\end{array}$ \\
\hline $\begin{array}{l}\text { II } \\
6-12\end{array}$ & Medium & $\begin{array}{l}\text { Medium Risk with Controls Verified. No mitigation } \\
\text { required where controls can be verified as functional. }\end{array}$ \\
\hline $\begin{array}{l}1 \\
1-5\end{array}$ & Low & Low Risk. No mitigation required. \\
\hline
\end{tabular}

Source: Adapted from Dethlefs \& Chastain, 2012. 


\section{RESULTS AND DISCUSSION}

In this chapter, the results from different stages of this risk study will be presented using a risk matrix as a tool of analysis and representation. The first part comprises an extensive review of well folders which is summarized in Table 18 in the section 4.2. The results of the frequency and consequence analyses are discussed in sections 4.4 and 4.5. Finally, main insights from risk ranking stage are presented in section 4.5.

\subsection{EXPLORATION WELL REVIEW}

The exploration wells were drilled between the years 1980 and 2013 in the offshore area of the state of Ceará, of which nine are located in the Ceará basin and five in the Potiguar basin as seen in Figure 6 .

Most of them were drilled in deep and ultra-deepwater, down to $2000 \mathrm{~m}$ of water depth, while a few wells are in water depth that hardly exceeds $100 \mathrm{~m}$. According to the drilling reports, drill bits ranging from 36 inches, for the first drilling phase, to 171/2 or $12_{1 / 4}$ in., for the last cased phase, were used to drill the borehole. $12_{1 / 4}$ and $81 / 2$ in diameter drill bits were used for open hole sections.

The main objective of the wells was to find commercially viable hydrocarbon accumulations in the turbidite sandstones of Ubaraná formation and in other Cretaceous rocks such as Paracaru and Mundau formation in the Ceará basin, and Pendencia, Alagamar and Açu formations in the Potiguar basin.

An analysis of the occurrences, causes, consequences observed in the drilling reports and some recommendations made by the operators to avoid similar facts in future wells to be drilled under similar conditions, is presented below: 
Figure 6 - Location of the wells studied along the coast of the state of Ceará, in the northeast of Brazil.

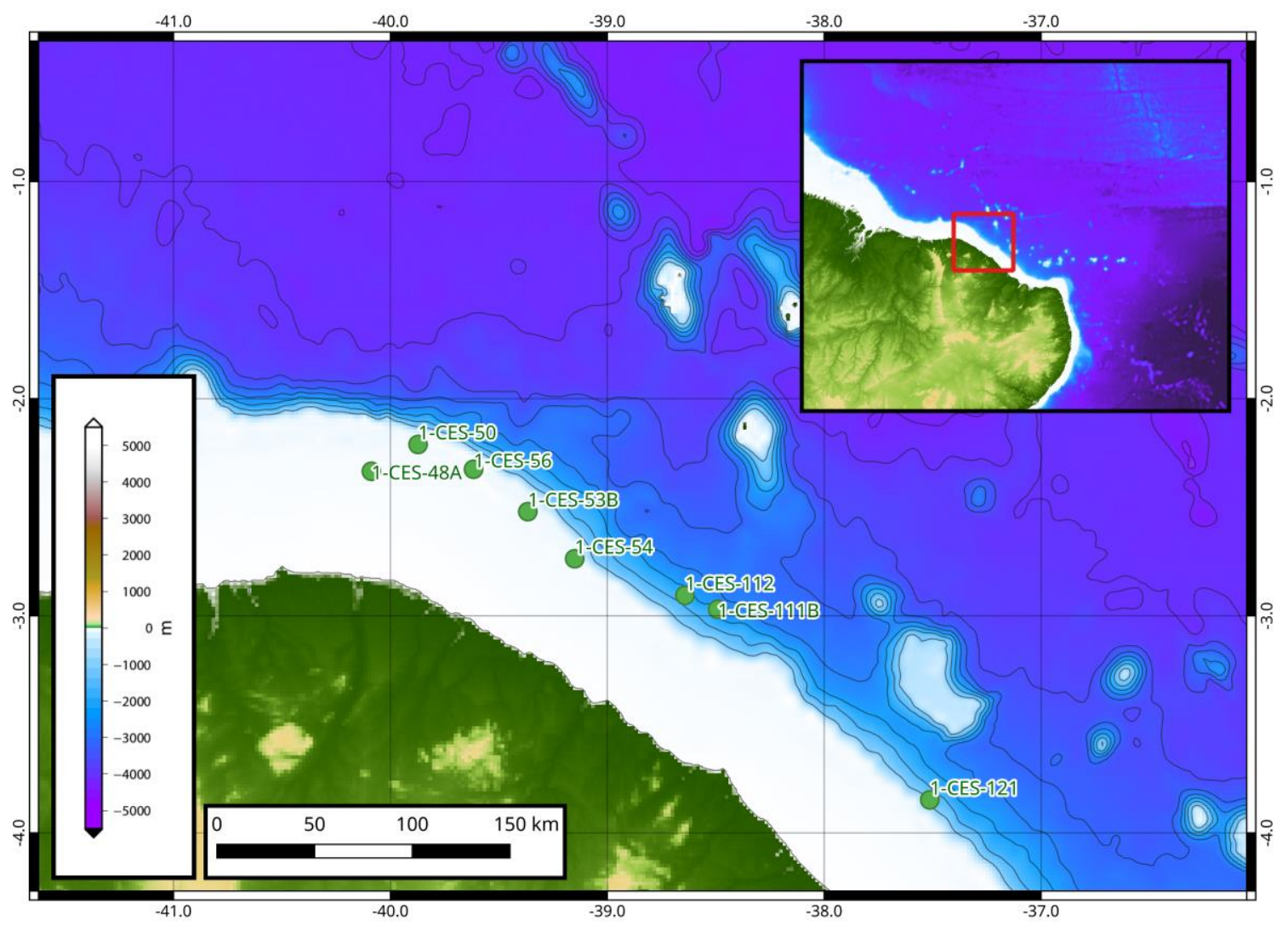

Source: Courtesy of Daniel Pavani.

\subsubsection{1-CES-48A well}

The drilling of the well 1-CES-48 began in January 1981 in the Acaraú area of the Ceará basin, with the objective of examining the sands of the Continental Sequence and of Unit B. The first phase of the operation went smoothly, the 20in-conductor being cemented at $181 \mathrm{~m}$. During the second phase problems of circulation loss was presented at 219 and $390 \mathrm{~m}$, the first successfully treated with a pill of obturating materials, while for the second it was necessary to pump a cement pill. However, the losses continued and were additionally accompanied by pipe sticking intents what led to abandon the well. At $420 \mathrm{~m}$, a cutter was lowered, with which 4 joints of the $20 \mathrm{in}$ lining were recovered and subsequently the probe was moved to a new area for drilling well 1-CES 48A. 
Like its predecessor, well 1-CES-48A was executed in four phases in which no adverse situations initially arose. The shoe of the conductor and surface casings were set at 169 and $300 \mathrm{~m}$ respectively. In the third phase, between 323 and $690 \mathrm{~m}$, the application of excessive pumping pressure caused hole enlargement in a poorly consolidated sandstone section.

Another wellbore stability problem was reported in $95 / 8$-in casing phase as the drilling fluid interacted with a reactive shale section resulting in hole closure. Consequently, additional time was spent to re-run drill pipes and drag increased at 1024 and $1828 \mathrm{~m}$.

In the last phase, hydrogen sulfide fractions were detected into the drilling fluid. The influx of this gas increased the penetration rate from 0.7 to $2.4 \mathrm{~m} / \mathrm{h}$ and reduced the fluid density from 10.2 to $8 \mathrm{lb} / \mathrm{gal}$ at $3015 \mathrm{~m}$ and the 11 to $7.0 \mathrm{lb} / \mathrm{gal}$ at $3064 \mathrm{~m}$. More details of the well and a drilling problem summary are featured in Tables 4 and 5 respectively.

Table $4-$ General information of the 1-CES-48A well.

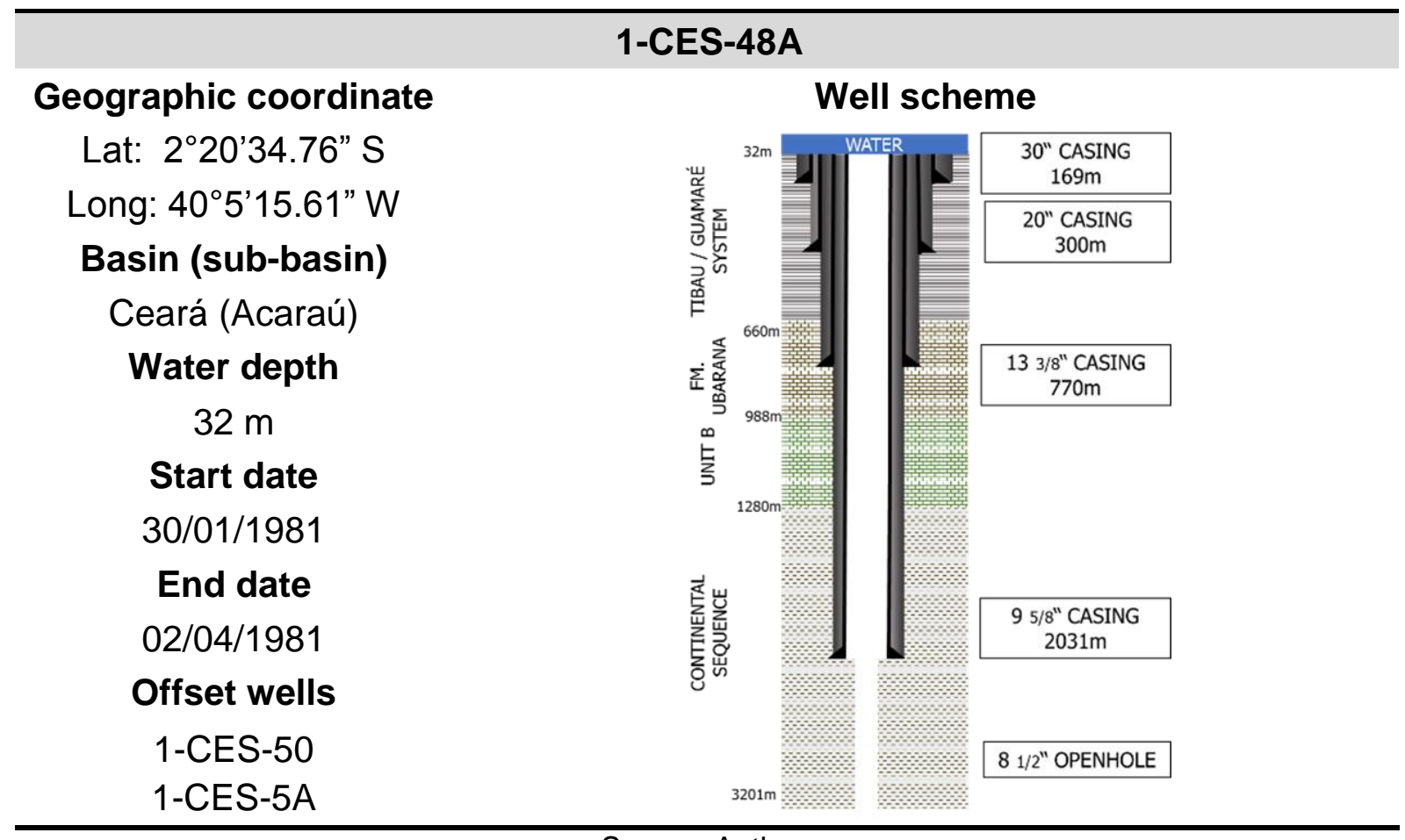

Source: Author. 
Table 5 - Drilling problems in the 1-CES-48A well.

\begin{tabular}{|c|c|c|c|}
\hline Depth & Description & Cause & Formation \\
\hline $169-300 m$ & Hole washout & $\begin{array}{l}\text { Excessive hydraulic horsepower. } \\
\text { Pump pressure } 800 \text { psi, flow rate } \\
1020 \text { and } 1200 \mathrm{gpm} .\end{array}$ & Tibau/Guamare \\
\hline $1024,1828 m$ & Hole closure & Reactive rocks (shale) & $\begin{array}{l}\text { Unit B, } \\
\text { Continental } \\
\text { sequence }\end{array}$ \\
\hline $3015,3064 m$ & $\begin{array}{l}\text { Sour gas } \\
\text { influx }\end{array}$ & $\begin{array}{l}\text { Hydrogen sulfide-bearing rocks. } \\
\text { ROP } 0.7 \text { to } 2.4 \mathrm{~m} / \mathrm{h}\end{array}$ & $\begin{array}{l}\text { Continental } \\
\text { sequence }\end{array}$ \\
\hline
\end{tabular}

Source: Author.

\subsubsection{1-CES-50 well}

The drilling of well 1-CES-50 was marked by severe cases of return loss and drilling fluid contamination with hydrogen sulfide. Earlier incidents occurred in the second phase (20-in casing) when the increasing fluid weight caused partial losses of 15 to 20 $\mathrm{bbl} / \mathrm{h}$. The density of the fluid, and consequently the fluid losses, was decreased from 8.7 to $8.4 \mathrm{lb} / \mathrm{gal}$ by adding diesel oil. The 20 -in casing got stuck at $286 \mathrm{~m}$, while running, so it was cemented at this depth, instead of at $308 \mathrm{~m}$, as planned.

Despite the implementation of different contingency measures such as the pumping of cement buffers, the use of sealant materials and drilling with seawater, the circulation losses during the third phase were not satisfactorily controlled and extended to the depth of $720 \mathrm{~m} .133 / 8$-in casing is run and cemented at $711 \mathrm{~m}$.

In the fourth phase, the losses continued and were accompanied by wellbore stability problems, which further increased the costs of the phase. The report indicated the collapse of the hole walls at $750 \mathrm{~m}$ and occurrence of hole closure at $1254 \mathrm{~m}$, what increased the risk of pipe sticking. The incidents were handled by increasing mud weight and adding asphalt. However, pipe sticking case was reported at $2209 \mathrm{~m}$ as the bit passed through a good-permeability sandstone intercalated with silty shale and siltstone section, with the following geological sequences: 2067 - 2106 (60\% sand), 2106-2160 (80\% Sand), 2160-2208 (80\% sand). The incident occurred during the execution of a short trip done to verify the cleaning conditions of the well, which was 
poorly communicated within the team. During the operation, the kelly system was removed, noting drilling fluid coming out through the pipe, possibly due to the accumulation of cuttings in the wellbore. Hydrogen sulfide was also detected into the drilling fluid what led to the use of caustic soda and caustic potash, increasing drilling phase costs.

Initially, the problem was handled as a differential sticking, by using pipe-freeing agents mixed with diesel, u-tube effect, bumper subs, and jars. All the previous ones without success. Consequently, the free point was estimated and back-off was executed with $125000 \mathrm{lbf}$ to recover as much of drillstring as possible. The result was one drill collar recovered and $189 \mathrm{~m}$ (620ft) of fish. Subsequently, washing operations were carried out without success, in which the washing pipe was also lost. The team then decided to place a cement plug at $1897 \mathrm{~m}$ and sidetrack the well. Finally, it was concluded that the problem could be caused by a jammed stabilizer (keyseat) or a sudden reduction of the borehole diameter.

An aspect to improve here was the poor communication with the main players, not pooling their observations and failing to reach a collective decision at the appropriate time. The incident would have probably been prevented if the pipe had been kept moving during the short trip saving considerable drilling time. More details of the well and a drilling problem summary are shown in Tables 6 and 7 respectively. 
Table 6 - General information of the 1-CES-50 well.

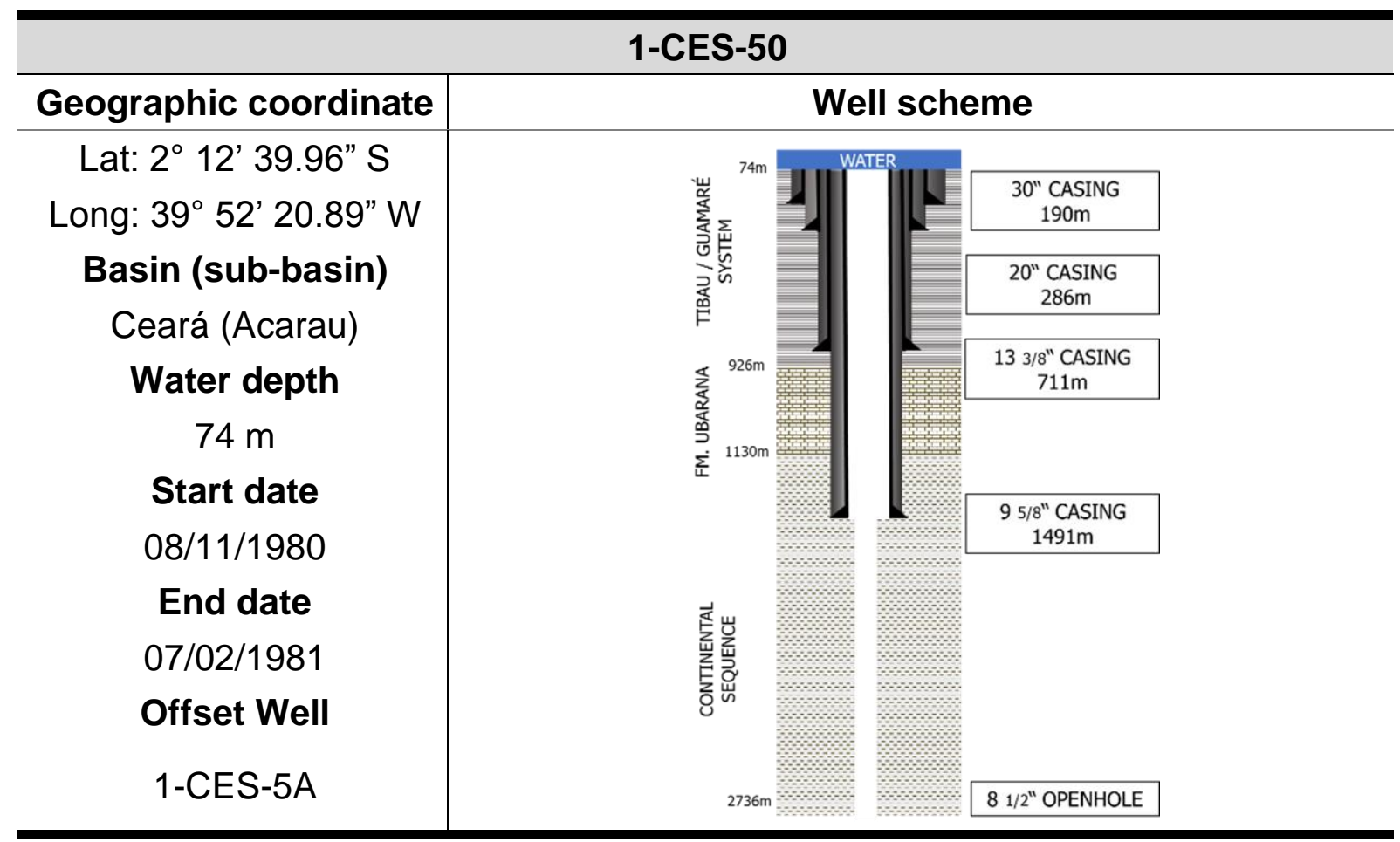

Source: Author.

Table 7 - Drilling problems in the 1-CES-50 well.

\begin{tabular}{cccc}
\hline Depth & Description & Cause & Formation \\
\hline $\mathbf{2 0 0 - 7 2 0 ~} \mathbf{m}$ & $\begin{array}{c}\text { Partial fluid loss } \\
(15-20 \text { bbl/h). }\end{array}$ & High fluid weight, 8.7ppg & Tibau/Guamare \\
\hline $\mathbf{7 5 0 m}$, & $\begin{array}{c}\text { Hole instability: } \\
\text { washout }{ }^{1} \text { and } \\
\text { narrow }\end{array}$ & $\begin{array}{c}\text { Reactive rocks and low fluid } \\
\text { weight. }\end{array}$ & $\begin{array}{c}\text { Tibau/Guamare } \\
\text { Continental } \\
\text { sequence }\end{array}$ \\
\hline $\mathbf{1 2 5 0 m}$ & Sour gas influx & $\begin{array}{c}\text { Hydrogen sulfide (H2S)- } \\
\text { bearing rocks. }\end{array}$ & $\begin{array}{c}\text { Continental } \\
\text { sequence }\end{array}$ \\
\hline $\mathbf{2 2 0 9 m}$ & Stuck pipe & $\begin{array}{c}\text { Pipe get stuck as kept static } \\
\text { during a short trip. The poor } \\
\text { communication between the } \\
\text { operators and the main } \\
\text { players of the well was an } \\
\text { aggravating. }\end{array}$ & $\begin{array}{c}\text { Continental } \\
\text { sequence }\end{array}$ \\
\hline
\end{tabular}




\subsubsection{1-CES-53B well}

The drilling risk events during appeared in the second phase with the occurrence of a total loss of circulation at $202 \mathrm{~m}$. The problem was handled with lost-circulation materials and cement without success. The cementing of the casing $20 \mathrm{in}$ was also carried out with difficulty, which caused additional lost time.

New fluid losses were reported in the interval $503-517 \mathrm{~m}$ of the third phase as using an aerated fluid as a drilling fluid. However, due to the influx of seawater into the system afterward, drilling fluid was circulated without air.

In the fourth phase, drilling problems were caused by the presence of clay sections. Between 1887 and $2005 \mathrm{~m}$ the well was reamed due to the collapse of the borehole walls. At $2400 \mathrm{~m}$, new well cavings were found so reaming/wiper trips were required in the $2313 / 2400$ interval and fluid weight was increased to from 9.8 to 10.8ppg.

Then, 21.5 hours were required to conditionate the well to the final well logging run, due to the occurrence of new cavings and fluid contamination at $2400 \mathrm{~m}$. The fluid was treated with zinc oxide and densified from 10.3 to $11 \mathrm{lb} / \mathrm{gal}$. Despite incidents, 95/8in casing was successful run and cemented at $2400 \mathrm{~m}$.

The problems of well instability continued in the final phase. New cases of cavings and mud contamination were indicated at 2410 and $2444 \mathrm{~m}$ respectively. Fluid weight reached 12.8ppg due to the detection of a high pore pressure zone what increased drilling fluid costs significantly.

Density, resistivity and sonic log response positively indicated the presence of abnormally high pressure in Cretaceous shale/sandstone sequence as a result of a process of under compaction. In the normally pressured section, the sonic log response showed a straight linear trend when plotted semilog versus depth as shown in Figure 7. Normally compacted formations are generally found in the topside section of wells where sediments are not sufficiently confined to disturb equilibrated migration of formation fluids. On the other hand, in zones of abnormally high pressure, the log 
measurements decrease and move away from the trend line significantly, indicating an increase of porosity.

It should be noted that log responses are not the only indicators of abnormal high pressures. The geothermal gradient in these zones tends to be accentuated, whereas in normally compacted formations the trend is constant. This is possibly due to the greater volume of conductive fluid retained in the porous space of the rock. Electrical log measures showed the highest temperature point ( $\left.185^{\circ} \mathrm{F}\right)$ in the 1 -CES53B's abnormally pressured zone where the geothermal gradient increased from 44 ${ }^{\circ} \mathrm{F} / \mathrm{km}$ to $55.6^{\circ} \mathrm{F} / \mathrm{km}$. More details of the well and a drilling problem summary are shown in Table 8 and Table 9 respectively.

Figure $7-$ Sonic profile indicating a high-pressure zone (in red) in the 1-CES-53B well.

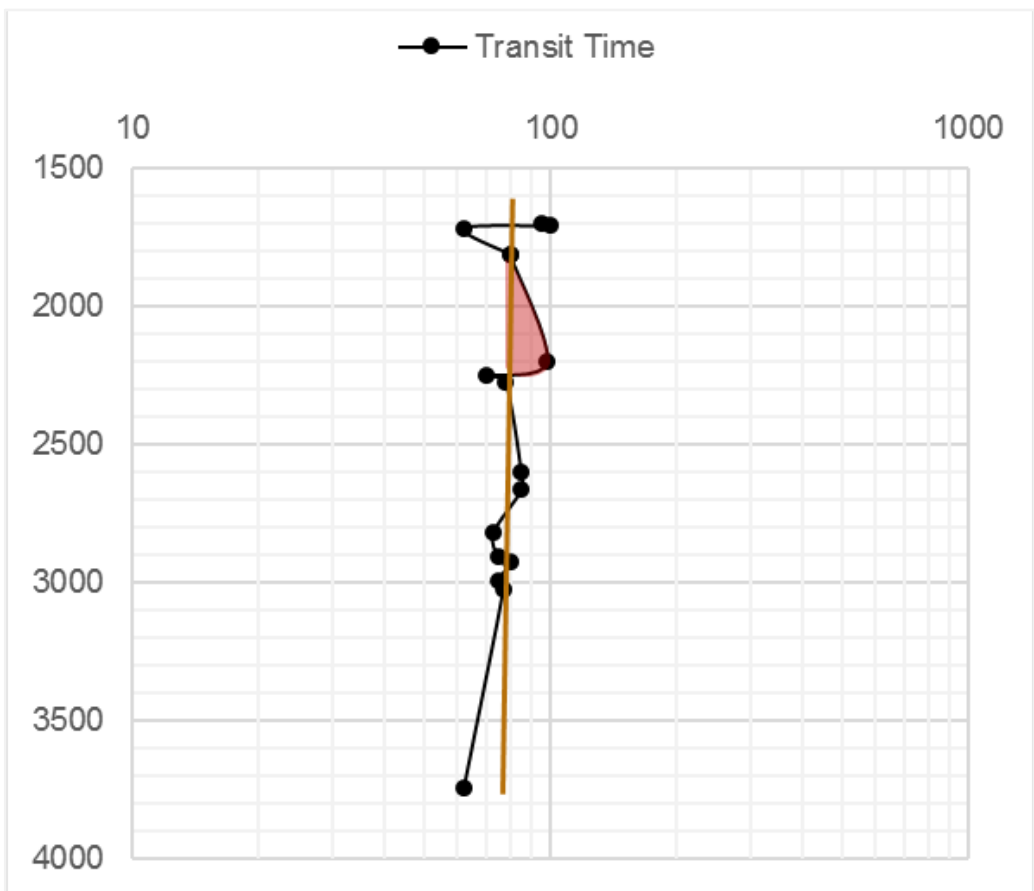

Source: Extracted from DVD-003800, ANP BDEP (2016) 
Table 8 - General information of the 1-CES-53B well.

\begin{tabular}{|c|c|c|c|}
\hline \multicolumn{4}{|c|}{ 1-CES-53B } \\
\hline Geographic coordinate & \multicolumn{3}{|c|}{ Well scheme } \\
\hline Lat: $2^{\circ} 31^{\prime} 14.48 " \mathrm{~S}$ & & & \\
\hline Long: $39^{\circ} 21^{\prime} 59.51^{\prime \prime} \mathrm{W}$ & & 击 & $\begin{array}{l}30 " \text { CASING } \\
178 \mathrm{~m}\end{array}$ \\
\hline Basin (sub-basin) & & 韭 & 20" CASING \\
\hline Ceará (Acarau) & 蛋 & 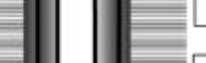 & $461 \mathrm{~m}$ \\
\hline Water depth & & 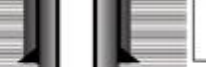 & $\begin{array}{l}13 \text { 3/8" CASING } \\
994 \mathrm{~m}\end{array}$ \\
\hline $52 \mathrm{~m}$ & & & \\
\hline Start date & & & $95 / 8^{\prime \prime}$ CASING \\
\hline 03/06/1981 & & 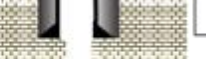 & $2393 \mathrm{~m}$ \\
\hline End date & & 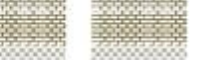 & \\
\hline $30 / 08 / 1981$ & & & \\
\hline Offset Well & 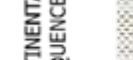 & & \\
\hline 1-CES-41 & 害出 & & \\
\hline 1-CES-54 & & & $81 / 2^{\prime \prime}$ OPENHOLE \\
\hline
\end{tabular}

Source: Author.

Table 9 - Drilling problems in the 1-CES-53B well.

\begin{tabular}{cccc}
\hline Depth & Description & Cause & Formation \\
\hline $\mathbf{2 0 2 m}$ & Total fluid loss & High fluid weight & Tibau/Guamare \\
$\mathbf{5 0 3 - 5 1 7 m}$ & Hole instability: hole narrow & Reactive formation & Ubarana \\
$\begin{array}{c}\mathbf{2 0 0 5 m , 2 4 0 0 m} \\
\mathbf{2 4 1 0 m}\end{array}$ & and cavings & $\begin{array}{c}\text { Sour-gas-bearing } \\
\text { zones }\end{array}$ & Ubarana \\
\hline $\mathbf{2 4 0 0 m}$ & Sour gas influx & & \\
$\mathbf{2 4 4 4 m}$ & & & \\
\hline
\end{tabular}

Source: Author

\subsubsection{1-CES-54 well}

According to 1-CES-54's well folder, the first cause of lost time appeared in the third phase (casing $133 / 8$ ). At $788 \mathrm{~m}$, losses of circulation occur. At $1443 \mathrm{~m}$ the well logging tool gets stuck at a silt/clay/marl interval and it was removed successfully. 
During the fourth phase, it was necessary $55000 \mathrm{lbf}$ to remove the drill string from the wellbore at $2089 \mathrm{~m}$ because of flocculation of the drilling fluid. The phenomenon was possibly generated by low shear rate through annular space.

However, most of the lost time was consumed on reaming/wiper trips and contaminated fluid treatment, as indicated in the sections 1826/2781 m and 2343/2779 $\mathrm{m}$, respectively.

During well testing activities, drill pipe section got stuck at $2752 \mathrm{~m}$. Some fishing operations such as jarring and backing off were used without success. New wiper trips were made in the intervals 2753/2784, 2865/2873, 3150/3168, 2636/2687, 2677/2700 $\mathrm{m}$. More details of the well and a drilling problem summary are shown in Table 9 and Table 10 respectively.

Table $9-$ General information of the 1-CES-54 well.

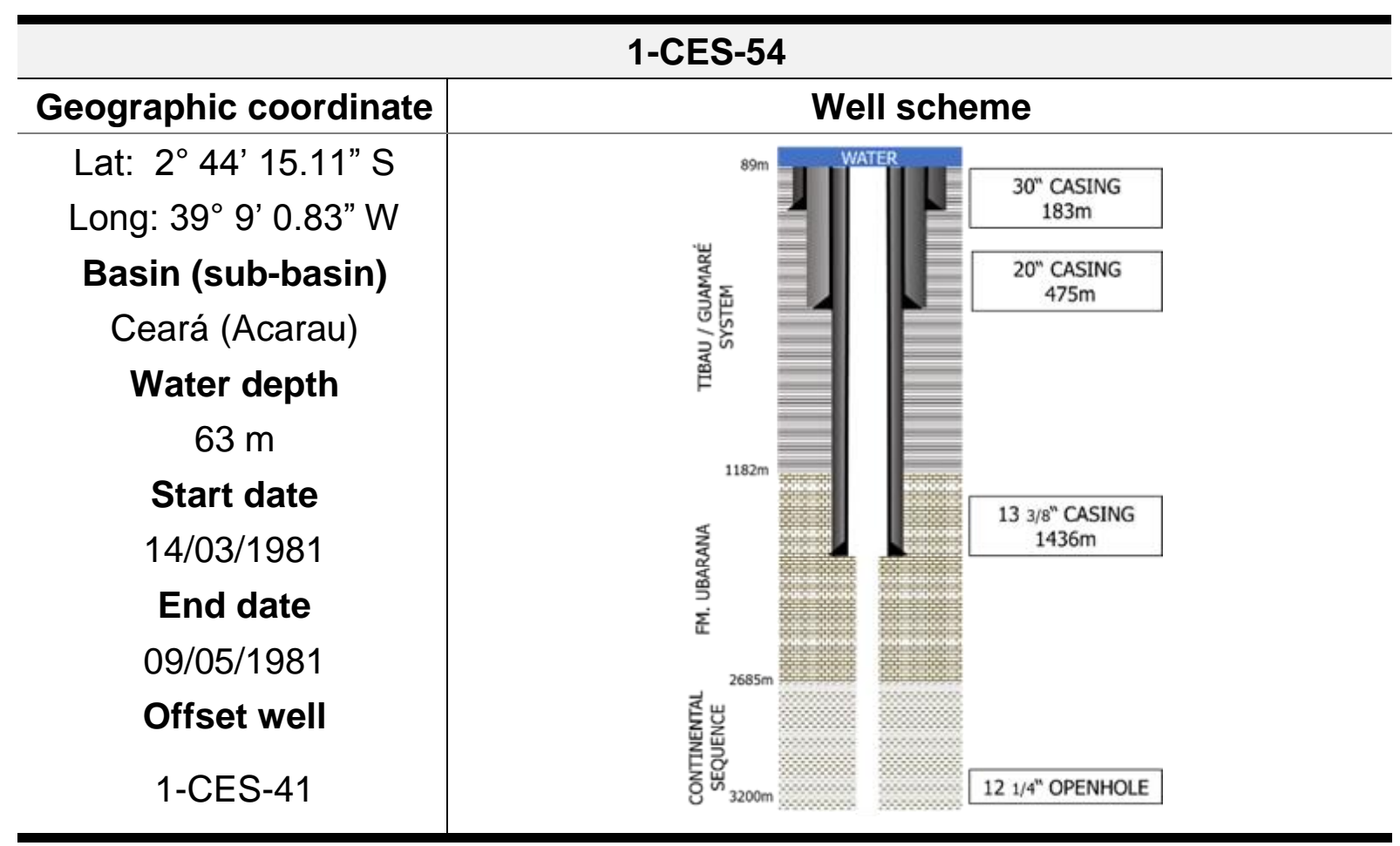

Source: Author. 
Table $10-$ Drilling problems in the 1-CES-54 well.

\begin{tabular}{cccc}
\hline Depth & Description & Cause & Formation \\
\hline $\mathbf{7 8 8 m}$ & Fluid loss & Thief zone & Tibau/Guamare \\
\hline $\mathbf{1 4 4 3 \mathbf { m } ^ { 1 }}$ & ${\text { Logging tool }{ }^{1} \text { and pipe }}^{\mathbf{2}}$ & Reactive formation & $\begin{array}{c}\text { Ubarana, } \\
\text { Continental seq. }\end{array}$ \\
\hline $\begin{array}{c}\mathbf{2 3 4 3}- \\
\mathbf{2 9 9 7 m}\end{array}$ & Sour gas influx & $\begin{array}{c}\text { Sour gas bearing } \\
\text { formation }\end{array}$ & $\begin{array}{c}\text { Continental } \\
\text { sequence }\end{array}$ \\
\hline
\end{tabular}

Source: Author.

\section{1 .5 1-CES-56 well}

The first incident reported from the 1-CES-56 well was loss of circulation caused by increasing drilling fluid weight to $9.3 \mathrm{ppg}$. At 503m, new losses occurred which decided to install $20 \mathrm{in}$-casing at $481.44 \mathrm{~m}$ instead of $500 \mathrm{~m}$.

Other losses between 15 and $40 \mathrm{bbl} / \mathrm{h}$ occurred in the third phase. Losses were controlled and reduced to values below $10 \mathrm{bbl} / \mathrm{h}$. In spite of existing unstable formations, the construction of an open hole section of two diameters (12 $1 / 4$ and $81 / 2$ in) was successful thanks to the optimal conditions of the drilling fluid, however, it is recommended to avoid this type of "funnels" so as not to compromise the wellbore stability.

Another cause of lost time was the fishing operations of a drill cone at $2736 \mathrm{~m}$ which was fully recovered in two attempts using a magnet and junk basket. More details of the well and a drilling problem summary are shown in Table 10 and Table 11 respectively. 
Table $10-$ General information of the 1 -CES-56 well.

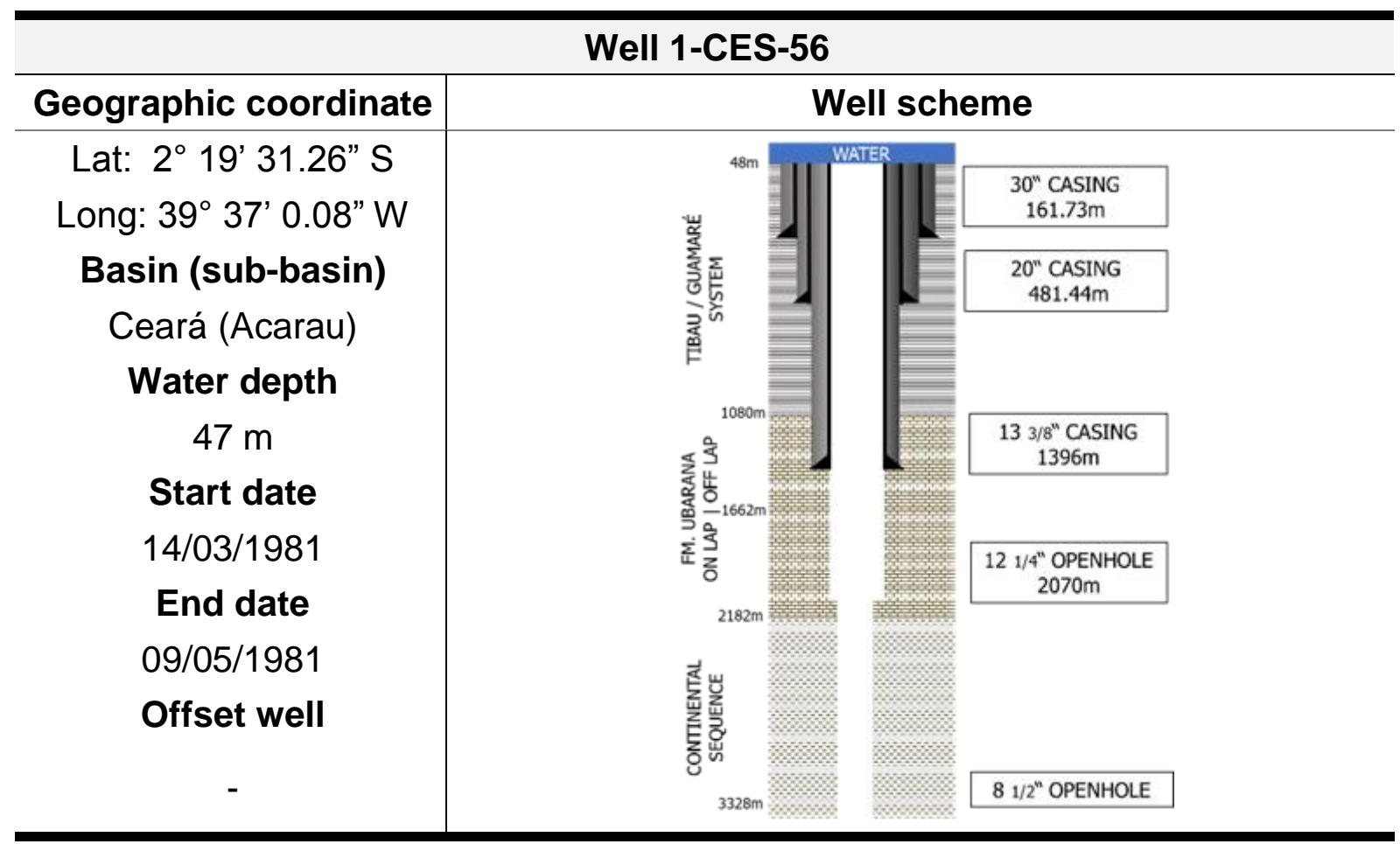

Source: Author.

Table 11 - Drilling problems in the 1-CES-56 well.

\begin{tabular}{|c|c|c|}
\hline Depth & Description & Formation \\
\hline 227- $236 m$ & $\begin{array}{l}\text { Total fluid loss } \\
\text { Cause: inadequate rheology and accumulation } \\
\text { of cuttings. High mud weight, } 9.3 \mathrm{ppg} \text {. }\end{array}$ & Tibau/Guamare \\
\hline $502 m$ & $\begin{array}{l}\text { Lost circulation (15 and } 40 \mathrm{bbl} / \mathrm{h} \text { ) } \\
\text { Cause: high mud weight. }\end{array}$ & Tibau/Guamare \\
\hline
\end{tabular}

\subsubsection{1-CES-111B well}

The first two attempts to initiate this pioneer well (1-CES-111 and 1-CES-111A) were abandoned due to the unconsolidated seafloor after the blowout preventer sank into the mud as installing the 20 -in casing.

After the second removal from the original location, the drilling was successfully started in February 1996 with a 16-day delay. 
The well was programmed to achieve a final depth of $3814 \mathrm{~m}$ through 4 drilling phases: $30,20,133 / 8$ and $81 / 2$ in, which are described below:

The first stages of the well were executed without any setback, leaving the conductor and surface casing shoes positioned at 1853 and $2139 \mathrm{~m}$ respectively.

The 16-in hole section was not foreseen in this pioneer, but due to the leakoff test performed at 1431 and $2251 \mathrm{~m}$ revealing equivalent weights too low for the safety of the phase, it was decided to widen the bit from $12_{1 / 4}$ to 16 in and to install $13_{3 / 8}$-in casing. Immediately after the first leakoff test, at a depth of $2175 \mathrm{~m}$, a total loss of circulation was observed.

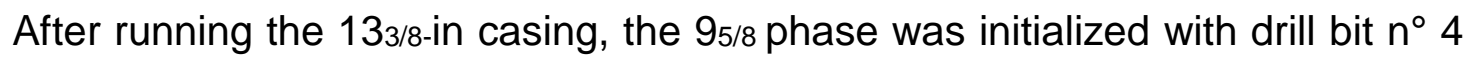
type S33SF. Once the drill bit reached $2271 \mathrm{~m}$, a new leakoff test was done resulting in an equivalent weight still low (9.5ppg), what led to the decision to drill at a controlled rate.

During this phase, two cores were collected. Whilst drilling the first core at $2362 / 2367 \mathrm{~m}$ pump pressure dropped and torque increased, which led to removing the drill string. It was also carried out the intermediary open hole logging runs without any occurrences.

The lowering of 9-5/8-in casing and its respective cementation was executed without abnormalities, being the shoe at $3056 \mathrm{~m}$.

Once the final depth was reached, the well was reconditioned to run the final well logging. During the second run, the tool got stuck and it was necessary to use an overshot to recover the fish. More details of the well and a drilling problem summary are shown in Table 12 and Table 13 respectively. 
Table 12 - General information of the 1-CES-111B well.

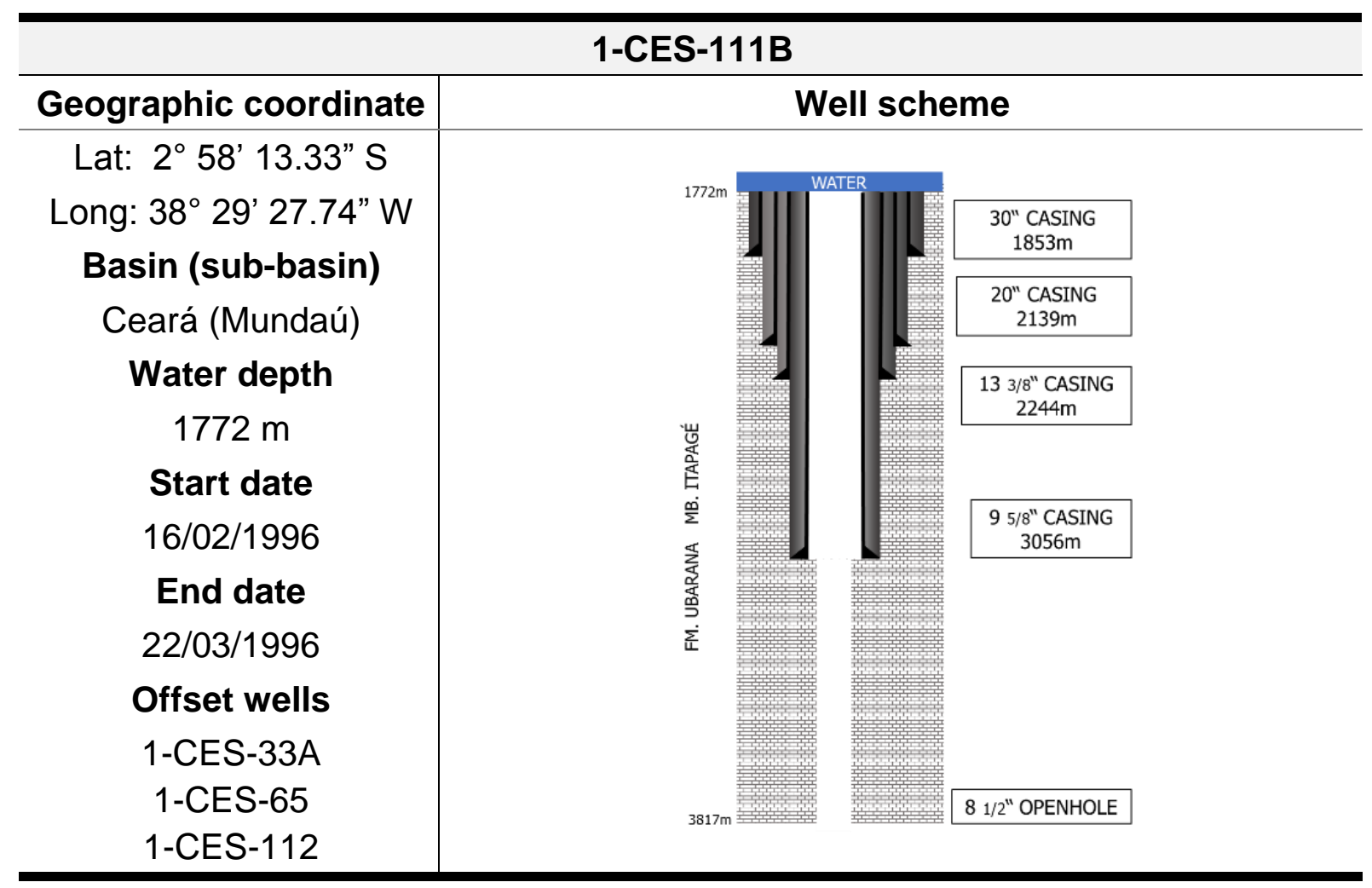

Source: Author.

Table 13 - Drilling problems in the 1-CES-111B well.

\begin{tabular}{cccc}
\hline Depth & Description & Cause & Formation \\
\hline $\mathbf{2 1 7 5} \mathbf{~}$ & Total lost circulation. & $\begin{array}{c}\text { Low-pore-pressure zone, } \\
9.5-9.8 \text { ppg. }\end{array}$ & Ubarana \\
\hline $\mathbf{3 8 1 4} \mathbf{~}$ & Stuck well logging tool & Reactive formation & Ubarana \\
\hline \multicolumn{4}{c}{ Source: Author. }
\end{tabular}

\subsubsection{1-CES-112 well}

This deepwater well, located $65 \mathrm{~km}$ away from the NE coast of the Curima field, aimed to examine the deposits of the rift section, producer formations in the shallow part of the Basin, and the neo-Cretaceous turbiditic sandstones with good permoporosity conditions.

The first cause of lost time during the operation was the strong ocean currents (2 knots) of the region that moved the drill ship 20 mi away from the location. The 
running of the 20-in casing was started as the vessel returned, however, the action was interrupted for more than one hour and resumed only after a sufficient approach to the wellhead. During the third phase, excessive accumulation of cuttings in the annulus increased considerably the circulation time necessary for cleaning of the hole.

At the beginning of $17_{1 / 2}$-in phase, cement, casing shoe and 27 meters of formation were drilled using only a $13_{3 / 4}$-in drill bit. After the completion of the leakoff test, the drill column was removed and 17/2-in under reamer added to the BHA, aiming to drill and lengthen the borehole simultaneously.

In the next phase, before installing the13/8-in casing, it was necessary to make sure the hole is in gauge. Contrary to what was expected, 4-arms-caliper log readings revealed narrowings in some intervals of the hole what led to performing wiper trips. There was a total of four caliper log runs, wherein two of these the tool indicated a diameter of $10.5 \mathrm{in}$ at $2430 \mathrm{~m}$. Considering the struggle to get wellbore walls stabilized, even performing many wiper trips, an under-reamer with a 181/2in aperture was used and tripped three times for each drill pipe. These preparations for $13_{3 / 8}$-in casing installation extended for four days.

At $1668 \mathrm{~m}$, circulation losses were induced by the surging effect resulting from running the drill string too fast in the hole. The consequences include more than 30 hours handling the incident, consumption of lost circulation material and effects on quality of the $133 / 8$-in casing cementation.

The presence of a fish (under reamer cone) left in the hole during the enlargement that preceded lowering of the $133 / 8$-in casing affected on the normal advance of the 121/4-in phase, leading to run a reverse circulation junk basket. However, the fish was only recovered after 22 hours of operation with over-shot.

During a short trip at $3702 \mathrm{~m}$ intending to prepare the borehole for intermediary well logging, it was also noted high drags and obstruction of annular space by cutting accumulation. These facts resulted in pipe sticking incident after drilling $925 \mathrm{~m}$ in almost $120 \mathrm{~h}$ with the same drill bit and without executing any short trip. 
Finally, at the beginning of $81 / 2$-in phase, high torques were observed due to the presence of iron in the hole, being carried out cleaning operations with basket sub. More details of the well and a drilling problem summary are shown in Table 14 and Table 15 respectively.

Table 14 - General information of the 1-CES-112 well.

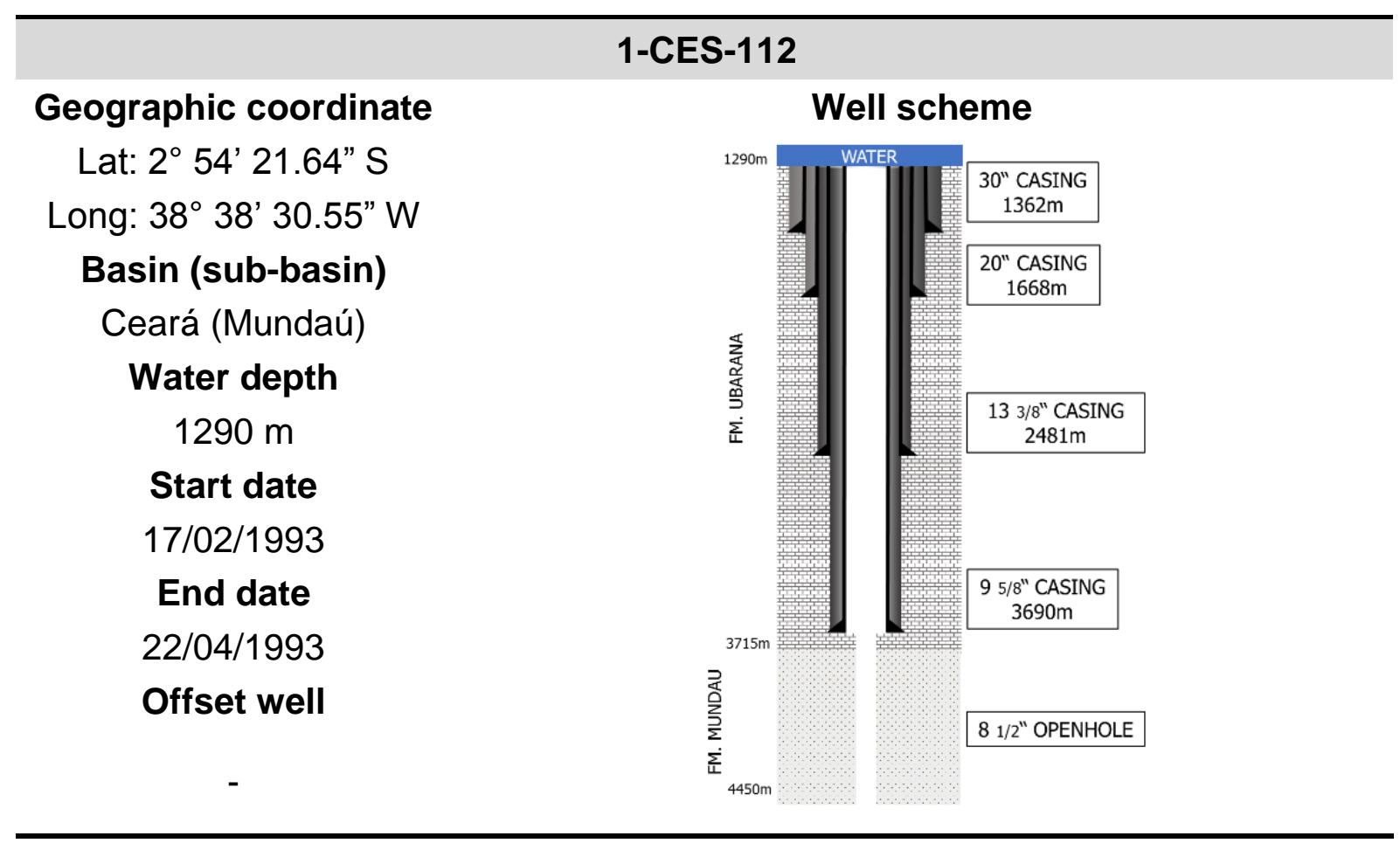

Source: Author.

Table 15 - Drilling problems in the 1-CES-112 well.

\begin{tabular}{cccc}
\hline Depth & Description & Cause & Formation \\
\hline $\mathbf{1 6 6 8 m}$ & Induced fluid loss (25bbl/min) & Surging effect & Ubarana \\
$\mathbf{1 9 4 7 m}$ & Poor hole cleaning & Cutting accumulation & Ubarana \\
$\mathbf{2 4 9 3 m}$ & Wellbore instability: narrowing & Reactive formation & Ubarana \\
$\mathbf{3 6 8 7 m}$ & Fluid conditioning & $\begin{array}{c}\text { Mud contaminated with } \\
\text { cement }\end{array}$ & Ubarana \\
$\mathbf{3 7 0 2 m}$ & Pipe sticking & Cutting accumulation & Ubarana \\
\hline
\end{tabular}




\subsubsection{1-CES-121 well}

The pioneer 1-CES-121 is $70 \mathrm{~km}$ away from the coast and is located in the basin of Potigar, in the state of Ceará; in the northwest area of Baixo Aracatí (see the geographical coordinates in Table 16).

Its purpose was to test the presence of structured turbid sandstones on a faulty domed paleo-geomorphic origin, caused by late tectonic reactivation. It also had as objective to evaluate the capacity of generation and quality of the Alagamar and Pendencia formations.

Planned to a final depth of $4514 \mathrm{~m}$, this pioneer was drilled in 5 phases: 36,26 , $16,12_{1 / 4}$ and $81 / 2$ in, which will be described as follows:

After lowering jetting string with 30 -in casing and setting the casing shoe at $1137 \mathrm{~m}$, the 26 -in phase was started using an M11-typed drill bit. The operation was performed without problems until the final depth at $1422 \mathrm{~m}$.

The next phase, 133/8-in casing, started by cutting the cement in the interval $1396 / 1422 \mathrm{~m}$. At reaching $1690 \mathrm{~m}$, drilling fluid was circulated down for 30 minutes to remove high-ROP-derived cuttings. At 1834 and 1863m, there were 30-min circulations for hole cleaning.

At $1890 \mathrm{~m}$ partial loss of circulation was observed from which it was drilled at a controlled rate until $1986 \mathrm{~m}$.

High torques and drilling times increasing from 1.5 to $45 \mathrm{~min} / \mathrm{m}$ led to finish the phase at $1988 \mathrm{~m}$ instead of $2000 \mathrm{~m}$ as planned.

After two hours of operation, a short trip was performed until the previous shoe. Mud circulation for 2 hours was executed, and drill column pulled out to run intermediary well log. However, in the first attempt of running, the tool encounter resistance at $1450 \mathrm{~m}$ to run down, being necessary to ream the hole.

After logging, routine procedures of casing running and cementation were performed without problems. The $13_{3 / 8}$-in casing shoe was set at $1976 \mathrm{~m}$. 
After cutting the shoe, it was drilled until $2001 \mathrm{~m}$ where a leakoff test is carried out resulting in a weight equivalent to $11.1 \mathrm{ppg}$.

At 3020 the drill column is pulled out from the hole for well logging. Coring was interrupted at $3024 \mathrm{~m}$ due to a significant increase in pump pressure. $59.5 \%$ of the sample representing exclusively a sandstone with no evidence of hydrocarbons were recovered.

When reaching the depth of $3041 \mathrm{~m}$, it was necessary to ream the $3040 / 3042 \mathrm{~m}$ interval several times due to the difficulty of drilling ahead. The next two meters were drilled with a low penetration rate. Subsequently, the multishot survey tool was freed with sand line and restarted running the drilling column which encountered resistance at $3513 \mathrm{~m}$.

New fishing operations were performed to recover the centralizer of the lateral sampling tool cannon found in the $3508 / 3519 m$ interval. Upon successful completion of the operation, it was lowered, cemented and tested 95/8-in casing without abnormalities.

After $12 \mathrm{~m}$ drilled in the last phase was carried out a leakoff test that indicated the equivalent weight of $13.9 p p g$.

At the depth of $3868 \mathrm{~m}$, mud circulation was made for drill trip and directional survey of the well, which indicated inclination of 6.5 degrees. $67 \mathrm{~m}$ later, a 400 -psi drop occurs in the pump pressure, forcing to pull the column out at a depth of $3935 \mathrm{~m}$. It was verified that the drop was caused by a hole on the 5 -in drill pipe body (washout).

The pressure drops continued until 4399m and resulted in approximately 15 pipe washouts. at $4512 \mathrm{~m}$, the column is pulled out for final well logging. The tool encounter resistance at 3915 so some wiper trips was executed. After circulating for two hours, a new logging attempt was done.

Once the tool was lowered, it was stuck at $4000 \mathrm{~m}$. After trying to free it, without success, applying 8000lb overpull, it was mounted overshot and lower down the fishing string. 
After fishing, was lowered column to conditionate the well in interval $3645 / 4512 \mathrm{~m}$. Then the final well logging was carried out and the well abandoned. More details of the well and a drilling problem summary are shown in Table 16 and Table 17 respectively.

Table 16 - General information of the 1-CES-121 well.

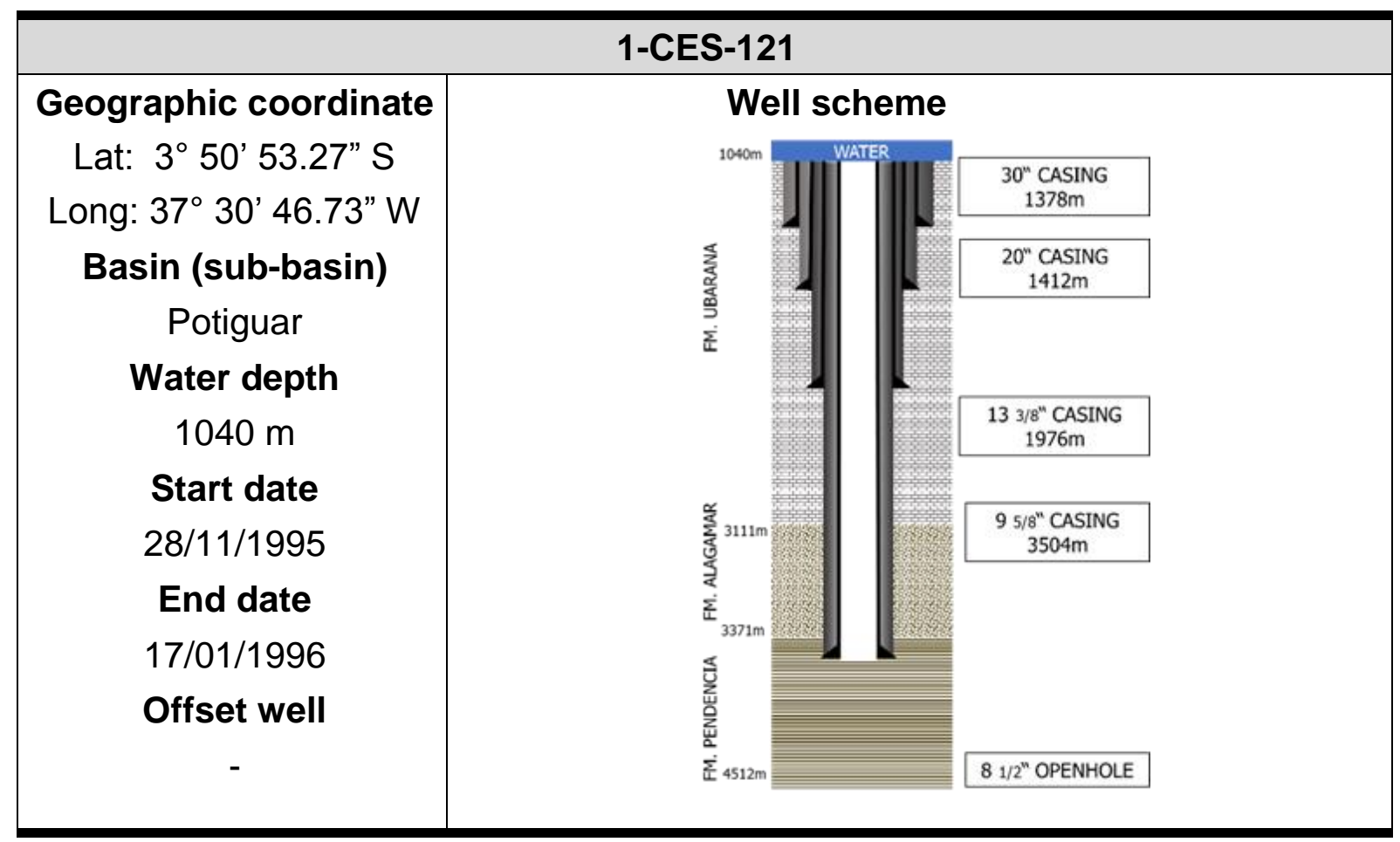

Source: Author

Table 17 - Drilling problems in the 1-CES-121 well.

\begin{tabular}{cccc}
\hline Depth & Description & Cause & Formation \\
\hline $\mathbf{1 8 3 4}, \mathbf{1 8 6 3} \mathrm{m}$ & Poor hole cleaning & High rate of penetration & Ubarana \\
\hline $\mathbf{1 8 9 0} \mathbf{m}$ & Partial fluid loss & $\begin{array}{c}\text { Excessive cutting } \\
\text { accumulation }\end{array}$ & Ubarana \\
\hline $\mathbf{4 0 0 0} \mathbf{m}$ & Logging tool sticking & Reactive formations & Pendencia \\
\hline \multicolumn{2}{c}{ Source: Author } & \\
& &
\end{tabular}




\subsection{RISK IDENTIFICATION}

The well folder review, summarized in Table 18 , revels $56 \%$ of the risk events identified are caused by environmental elements of the system. The environmental elements comprise geological and metocean conditions such as strong ocean currents, hydrogen sulfide-bearing formations, abnormally pressurized zones and watersensitive sections. The geological features were responsible for $87 \%$ of the drilling problems including mud contamination, stuck pipe and hole instability. Shales played an important role in pipe sticking and wellbore instability occurrence causing a half of the cases.

As a high current environment, rig drift-offs occurred in some drilling locations. environmental forces and rig power loss is typically addressed as min reason of this incident. According to the well folder, the cases were managed successfully no requiring riser disconnection.

On the other hand, operational hazards are associated with equipment and personnel-related problems such as inappropriate practices and work procedures. During the review, application of high mud pressure on the formation, excessive accumulation of cuttings in the annular and erosion caused $44 \%$ of the risk events identified. Other hazards include improper rig hydraulics (pump power, ROP) for efficient bottom and annular hole cleaning, surging effect resulting from running drill string into the hole too fast and improper stuck pipe procedures.

Based on well logging interpretations observed, it was possible to establish some connections between lithological description of the formations drilled and drilling problems observed as follow:

Tibau/Guamare system. Mainly composed of calcarenites and disaggregated and very-coarse-to-coarse-grained sandstones. These uncemented sandstones developed at shallow burial depths tend to be lost-circulation zones leading to fluid loss, caving and hole cleaning problems as seen in Table 18. 
Ubarana formation. Characterized by the presence of pelites and, subordinately, sandstones and carbonates. Clay-rich sediments are more prone to causing stuck pipe and hole stability problems because of sensitivity to the drilling fluid.

Continental sequence. The lithology found was fine to medium sandstones, argillites and secondly, siltstones; marlstones; calcilutites, calcarenites. Given to hydrocarbon indications in some intervals of this formation, hydrogen sulfide may be detected during the drilling process. This gas is extremely hazardous to the rig and site personnel and required special safety measures in the well planning phase.

Pendencia formation. Consisting of semi-hard to hard micaceous shale and, semi-friable fine to medium-grained sandstones. In hard/soft interbedded formations, like Pendencia, it is more prone to occurring hole gauge and stuck pipe problems due to constant appearance of micro-doglegs, areas where inclination and azimuth change, and bottom hole assembly reach more contact with the hole walls.

Other geological formations such as Unit B and Mundau and Alagamar, in deepwater wells, were observed. Little or no drilling problems associated with were found on well folders. However, it probably responded to the small sample of wells examined so that more geology-related problems must be considered on the prospective well drilling plan.

Table 18 - Summary of risk events identified.

\begin{tabular}{|c|c|c|c|c|}
\hline Risk event & Well name & Hazard & Classification & Geological unit \\
\hline \multirow{5}{*}{ Stuck pipe } & 1-CES-50 & String static as tripping & Operational & Continental seq. \\
\hline & 1-CES-54 & Reactive formations & Environmental & $\begin{array}{c}\text { Ubarana, } \\
\text { Continental seq. }\end{array}$ \\
\hline & 1-CES-111B & Reactive formations & Environmental & Ubarana \\
\hline & 1-CES-112 & Cuttings accumulation & Operational & Ubarana \\
\hline & 1-CES-121 & Reactive formations & Environmental & Pendencia \\
\hline \multirow{2}{*}{ Pipe washout } & 1-CES-112 & Erosion & Operational & - \\
\hline & 1-CES-121 & Erosion & Operational & - \\
\hline \multirow{3}{*}{$\begin{array}{l}\text { Loss of } \\
\text { Circulation }\end{array}$} & 1-CES-50 & High mud weight & Operational & Tibau/Guamare \\
\hline & 1-CES-53B & High mud weight & Operational & Tibau/Guamare \\
\hline & 1-CES-54 & Thief zone & Environmental & Tibau/Guamare \\
\hline
\end{tabular}




\begin{tabular}{|c|c|c|c|c|}
\hline & $\begin{array}{l}\text { 1-CES-56 } \\
\text { 1-CES-111B } \\
\text { 1-CES-112 } \\
1-C E S-121\end{array}$ & $\begin{array}{l}\text { Cutting accumulation } \\
\text { Low pore pressure } \\
\text { Surging pressure } \\
\text { Cutting accumulation }\end{array}$ & $\begin{array}{c}\text { Operational } \\
\text { Environmental } \\
\text { Operational } \\
\text { Operational }\end{array}$ & $\begin{array}{c}\text { Tibau/Guamare } \\
\text { Ubarana } \\
\text { Ubarana } \\
\text { Ubarana }\end{array}$ \\
\hline $\begin{array}{c}\text { Wellbore } \\
\text { Instabilities }\end{array}$ & $\begin{array}{l}1-C E S 48 A \\
1-C E S-53 B \\
1-C E S-50 \\
1-C E S-112\end{array}$ & $\begin{array}{l}\text { High hydraulic } \\
\text { pressure } \\
\text { High pore pressure } \\
\text { Unconsolidated and } \\
\text { reactive formations } \\
\text { Reactive formation }\end{array}$ & $\begin{array}{l}\text { Operational } \\
\text { Environmental } \\
\text { Environmental } \\
\text { Environmental }\end{array}$ & $\begin{array}{c}\text { Unit B, } \\
\text { Continental seq. } \\
\text { Ubarana } \\
\text { Tibau/Guamare, } \\
\text { Continental seq. } \\
\text { Ubarana }\end{array}$ \\
\hline $\begin{array}{l}\text { Sour Gas } \\
\text { Influx }\end{array}$ & $\begin{array}{l}\text { 1-CES-48A } \\
1-C E S-50 \\
1-C E S-53 B \\
1-C E S-54 \\
\end{array}$ & $\begin{array}{l}\text { Sour gas-bearing rocks } \\
\text { Sour gas-bearing rocks } \\
\text { Sour gas-bearing rocks } \\
\text { Sour gas-bearing rocks }\end{array}$ & $\begin{array}{l}\text { Environmental } \\
\text { Environmental } \\
\text { Environmental } \\
\text { Environmental }\end{array}$ & $\begin{array}{c}\text { Continental seq. } \\
\text { Continental seq. } \\
\text { Ubarana } \\
\text { Continental seq. }\end{array}$ \\
\hline $\begin{array}{l}\text { Poor Hole } \\
\text { Cleaning }\end{array}$ & $\begin{array}{l}1-C E S-112 \\
1-C E S-121\end{array}$ & $\begin{array}{l}\text { Cutting accumulation } \\
\text { Cutting accumulation }\end{array}$ & $\begin{array}{l}\text { Operational } \\
\text { Operational }\end{array}$ & $\begin{array}{l}\text { Ubarana } \\
\text { Ubarana }\end{array}$ \\
\hline Drift-Off & $\begin{array}{c}\text { 1-CES-111B } \\
1-C E S-112\end{array}$ & $\begin{array}{l}\text { Strong oceanic current } \\
\text { Strong oceanic current }\end{array}$ & $\begin{array}{l}\text { Environmental } \\
\text { Environmental }\end{array}$ & - \\
\hline
\end{tabular}

Source: Author.

\subsection{ANALYSIS OF FREQUENCY}

In little explored regions as BEM, drilling problems are expected to occur very frequently given the lack of correlation data. The frequency of these events is also governed by the interpretation of seismic data, quality of correlation data and prior experience of the well planner.

The analysis of drilling phases reflected clearly this question where several occurrences along with the drilling operation as shown in Figure 8. From 31 drilling phases examined, $35,5 \%$ presented some type of lost circulation; $19,4 \%$ sticking of pipe or logging tool; $19,4 \%$ wellbore stability problems. Positive readings of sour gas were detected in the drilling fluid of $12,9 \%$ of the phases examined. $6,5 \%$ indicated hole cleaning problems. 
Figure 8 - Percentages of occurrence of drilling hazards on the operation.

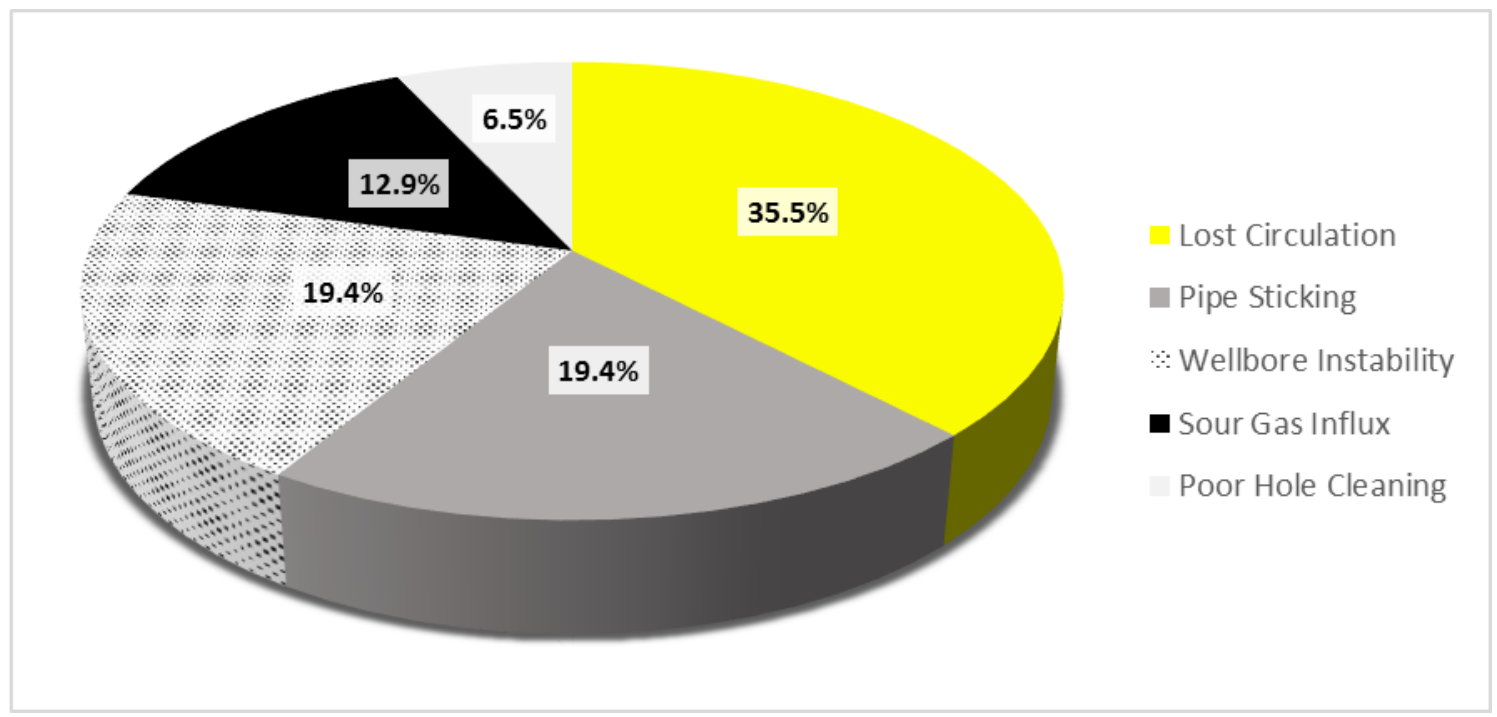

Source: Author

Occasional frequency - Loss of circulation was the most frequent occurrence in the well folders. Figure 9 shows most of the lost circulation cases occurred in the third drilling phase of the shallow water wells where the Tibau/Guamare lithological system were exposed. The poorly consolidated sandstones of this unit contain pores large enough to be sealed by the solids normally present in the drilling fluid. In this way, little or no filter cake, needed to prevent the loss of circulation to continue, is present on borehole walls. Other causes pointed to failures in the handling of drilling mud properties where often the accumulation of cuttings in the annulus resulted in increases in the internal pressure of the well that led to fluid losses into the formation.

Seldom frequency - Problems of wellbore stability and pipe sticking were associated with Ubarana formation shale sections exposed in the last drilling phases (IV e V). The use of water-based drilling fluid caused swelling and sloughing of shales resulting in partial or total obstruction of the borehole diameter. Reaming and fishing operations executed in response to the reactive-rock-related problems were the most common way of NPT reported on the well folders. Additionally, accumulation of swollen rock blocks induced to other wellbore problems such as poor hole cleaning due to the increasing volume of solids. 
Other seldom frequency event was hydrogen sulfide influxes into the well. The generation of this highly hazardous gas is associated with presence of organic material/hydrocarbons in the formation as observed in some intervals of Continental sequence and Ubarana formation turbidite sandstones according coring analysis. Despite containing hydrocarbons, several wells were abandoned as dry wells because of being interesting from the point of view of production.

Unlikely frequency - This category is occupied by the event "poor hole cleaning" with only two cases, reported at the Ubarana formation. Although this formation containing intervals prone to well stability problems that lead to the accumulation of cuttings in the annular, the incidents were caused by improper drilling practices.

Figure $9-$ Number of cases of drilling problems.

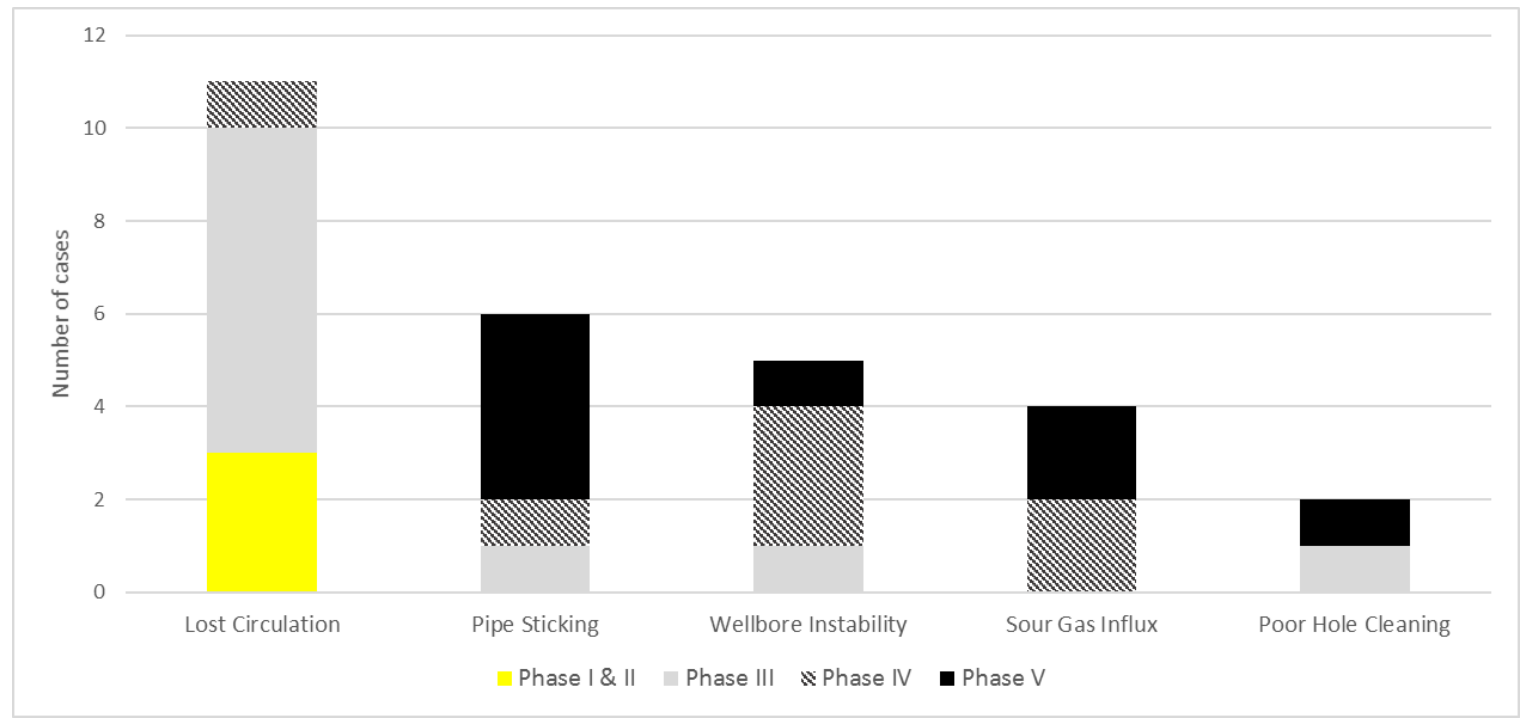

Source: Author.

\subsection{ANALYSIS OF SEVERITY}

The severity or impact of the drilling hazards was estimated based on previous experience and engineering judgment of the questionnaire participants. Every was divided into five categories: incidental, occurrences spending up to half day to be handled; minor, up to an entire day; moderate, loss of a well section as consequence; major, loss of more than one hole section; severe, loss of the entire well; and 
catastrophic, loss of rig. Table 19 shows the results of the questionnaire highlighting in yellow the level of severity assigned by the participants to each occurrence.

Table 19 - Event impact from questionnaire outcome.

\begin{tabular}{cccccc}
\hline & $\begin{array}{c}\text { Lost } \\
\text { Circulation }\end{array}$ & $\begin{array}{c}\text { Pipe } \\
\text { Sticking }\end{array}$ & $\begin{array}{c}\text { Wellbore } \\
\text { Instability }\end{array}$ & $\begin{array}{c}\text { Sour Gas } \\
\text { Influx }\end{array}$ & $\begin{array}{c}\text { Poor Hole } \\
\text { Cleaning }\end{array}$ \\
\hline Incidental & $14,3 \%$ & $9,5 \%$ & - & $42,9 \%$ & $14,3 \%$ \\
Minor & $23.8 \%$ & $28,6 \%$ & $19 \%$ & $33,3 \%$ & $23,8 \%$ \\
Moderate & $42,9 \%$ & $38,1 \%$ & $57,1 \%$ & $9,5 \%$ & $47,6 \%$ \\
Major & $14,3 \%$ & $19 \%$ & $19 \%$ & - & $14,3 \%$ \\
Severe & $4.7 \%$ & $4.8 \%$ & $4.9 \%$ & $4.8 \%$ & - \\
Catastrophic & - & - & - & $9,5 \%$ & - \\
\hline
\end{tabular}

Source: Author

As can be observed from Table 20, the severity of the drilling risk identified is not significantly high with the maximum level being moderate. Some inferences based on these findings:

The fact of lost circulation is considered as of medium severity means that it has the potential to generate the loss of a section of the well. However, in severe cases, as related in the second drilling phase of the pioneer 1-CES-48, this incident can lead to the abandonment of the well. 1-CES-48's losses of circulation did not respond to the displacement of lost-circulation materials and cement plugs. The well was relocated and a new type of string (30-in conductor) was added to the 1-CES-48A's casing program.

Pipe sticking was indicated as a moderate impact event. A clear example of its consequence is seemed on well 1-CES-50's report where a sidetrack was performed after numerous unsuccessful attempts to free the pipe from what appeared to be a case of differential sticking. It is worth mentioning that the decision on how long to continue attempting to retrieve stuck pipe vs. back off, plug back, and then sidetrack is generally an economic issue.

Although wellbore stability problems can lead to sticking of pipe and tools that resulted in the loss of a well section, most of the cases reported were solved with 
wiper/reaming trips causing only delay on the drilling program. Other consequences include failures during cementation and logging.

The evaluation of sour gas influx was very much in line with the observations. The incidents were generally solved in less of a half day by adding sulfide scavengers into drilling mud. However, this was the unique event to be indicated as of catastrophic impact on the questionnaire. This is because the hydrogen sulfide toxicity is as high as to cause sudden death from exposure to low concentrations of the substance. Additionally, this gas is highly corrosive and may add tremendous costs to the operation if the operator has not taken proper precautions (CARTER; ADAMS, 1979).

On the other hand, despite having a relatively simple treatment, inefficient hole cleaning has a greater impact on the operation since it can generate other problems such as pipe sticking and losses of circulation. High annular cleaning times increase flat times.

\subsection{RISK RANKING}

As explained above, risk results from combining the consequence severity of an event and its frequency. The result of this is a numerical value that allows ranking the risk within the risk matrix. In this study, risk levels range from 1 to 36 , being 36 for those events requiring new mitigation measures. It worth to mention that the rate of a drilling hazard is completely subjective and varies according to the causation of the event and consequences examined. Risks associated with environmental or human health were not considered so that the risk level of the events could be higher than expected.

As seen in Table 20, the losses of circulation occupied the most critical level, with a value of 15 . The uncontrolled mud losses during the operation indicated improvements in control and mitigation measures must be implemented. Considering mud losses were mainly caused by little precise wellbore pressure management, it is critical to maintaining the mud weight and equivalent circulating density (ECD) within safe operating limits defined by the formation fluid, collapse, and fracture pressures. Operating outside these limits keep leading to expensive lost circulation and even differential sticking and pack-off incidents. Technologies such as pressure-while- 
drilling (PWD) can be a good option. PWD provides more accurate downhole measurements of equivalent circulating density, hydrostatic pressure, and effective mud weight. Other applications include kick detection, swab/surge pressure monitoring while tripping and reaming and monitoring of hole cleaning.

Wellbore stability problems, pipe sticking, and inefficient hole cleaning were defined as medium-level risk events which mean that existing mitigation measures are acceptable. Wellbore stability problems were, most of the cases, successfully treated with constant wiper/conditioning trips, especially before lowering logging tools and casing pipes. These problems were associated with the presence of mobile and reactive formations, hence the importance of selecting appropriate mud system and ensuring compliance of drilling program throughout the entire operation. It is worth mentioning, rifted and transform fault blocks are characteristic of Equatorial margin basins what increase the possibility to drill through instable zones.

Although current control measures are functional, improvements at identifying pipe sticking causes are required to reduce the risk level of this hazard. Faults at problem diagnosis results in the application of unsuitable contingency actions. However, the emphasis is on prevention. It means watching warning signs and understand what combination of circumstances lead to a stuck pipe case. This is also applicable to handle hole cleaning problems due to one of the stuck pipe indications is the excessive accumulation of cuttings in the annular space of the well. And this is the primary cause of poor hole cleaning. 
Table 20 - Risk level of events examined.

\begin{tabular}{|c|c|c|c|c|c|}
\hline $\begin{array}{l}\text { Risk } \\
\text { event }\end{array}$ & 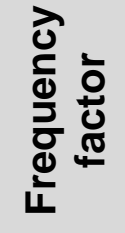 & Proposed measures & Consequences & 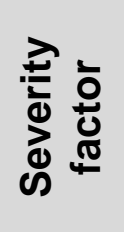 & 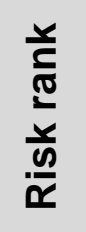 \\
\hline $\begin{array}{l}\text { Lost } \\
\text { Circulation }\end{array}$ & 5 & $\begin{array}{l}\text { Technologies such as pressure-while-drilling } \\
\text { (PWD) can be a good option. PWD provides } \\
\text { more accurate downhole measurements of ECD, } \\
\text { hydrostatic pressure, and effective mud weight. } \\
\text { Other applications include kick detection, } \\
\text { swab/surge pressure monitoring while tripping } \\
\text { and reaming and monitoring of hole cleaning. }\end{array}$ & $\begin{array}{l}\text { Even in less severe forms, the loss of fluid } \\
\text { to the formation represents a financial loss } \\
\text { as an additional volume of fluid must be } \\
\text { pump down. More severe cases can result } \\
\text { in formation fluids flowing into the } \\
\text { wellbore, differentially stuck pipe, the } \\
\text { collapse of borehole walls if } \\
\text { unconsolidated formations are exposed or } \\
\text { loss of the well section. }\end{array}$ & 3 & 15 \\
\hline $\begin{array}{l}\text { Pipe } \\
\text { Sticking }\end{array}$ & 4 & $\begin{array}{l}\text { Emphasis on prevention. It means watching } \\
\text { warning signs and understand what combination } \\
\text { of circumstances lead to a stuck pipe case. This } \\
\text { is also applicable to handle hole cleaning } \\
\text { problems due to one of the stuck pipe indications } \\
\text { is the excessive accumulation of cuttings in the } \\
\text { annular space of the well. }\end{array}$ & $\begin{array}{l}\text { Pipe irretrievably stuck may lead to loss of } \\
\text { the hole section requiring sidetrack. }\end{array}$ & 3 & 12 \\
\hline $\begin{array}{l}\text { Wellbore } \\
\text { Instability }\end{array}$ & 4 & $\begin{array}{c}\text { Selection of the appropriate mud system and } \\
\text { ensuring compliance of the drilling program } \\
\text { throughout the entire operation. }\end{array}$ & $\begin{array}{l}\text { The collapse of borehole walls may lead } \\
\text { to stuck pipe, hole cleaning problems, or, } \\
\text { in severe cases, loss of the well section. }\end{array}$ & 3 & 12 \\
\hline
\end{tabular}


Bad cementation and poor-quality logs also may occur.

Sour Gas

Influx

Mud weight monitoring. $\mathrm{H}_{2} \mathrm{~S}$ scavengers

Poor Hole

Cleaning
Hydraulics monitoring.
Hydrogen sulfide $\left(\mathrm{H}_{2} \mathrm{~S}\right)$ alter drilling fluid $\mathrm{pH}$ and is flammable at higher concentrations, as well as corrosive to metals. It is also extremely toxic to humans at minute concentrations.

Excessive accumulation of cutting increase circulation time of the well. lost circulation and stuck pipe incidents may occur. 


\section{CONCLUSION}

This work was aimed at conducting qualitative risk analysis for exploration drilling operations in the Brazilian Equatorial Margin using a risk matrix. This tool allowed to identify and rank the hazards associated with the drilling of exploration wells in the coast of Ceará state. The result from this is a clear risk picture of the drilling operation in the Region where the events of highest risk are presented, as shown in Table 20, so that further risk studies (risk evaluation) may be addressed to formulate riskreducing measures.

To achieve that, the risk analysis process comprises two steps: hazard identification and risk estimation. The first part summarizes the drilling problems found throughout well folder examination as illustrated in Table 18. Lost circulation, pipe sticking, wellbore instability, sour gas influx, and poor hole cleaning is regarded as the most relevant. As a risk event may derive from environmental and operational factors, this study reveals geological features such as sour formations, abnormally pressurized zones and reactive formations (shales) are the foremost causes of drilling problems in the area of study. Shale sections in the Ubarana formation are a highly critical aspect to consider at the last drilling phases and are likely to cause expensive stuck pipe and wellbore instabilities occurrences unless preventative measures are applied. Operational factors also play a significant role in NPT. Application of high mud pressure and excessive accumulation of cuttings are the most common causes of NTP during the drilling operation.

In the second part, the frequency and severity of risk events are calculated for estimating the risk. Frequency results from the number of times a risk event occurred per drilling phase. Severity or impact is assigned by a group of Industry leaders through a questionnaire. As a result, the risk estimation indicates that lost circulation is the most important concern as it was classified as a high-risk event. The poorly consolidated rocks of Tibau/Guamaré system were responsible for most of the cases. Other causes pointed to failures in the handling of drilling mud properties and excessive 
accumulation of cuttings that increased significantly the overbalance pressure on the formation.

Although it is a moderate severity problem, the high number of lost circulation cases reveals that improvements in preventative and mitigation measures must be done. If not, besides increasing NPT, severe losses of circulation may lead to borehole collapse, formation fluid influx and premature abandonment of the well. The implementation of new technologies and techniques such as pressurised mud cap drilling, wellbore stress approach into lost circulation plan and application of chemical sealant based lost circulation material; together with massive training program and adoption of strict well control procedures may help companies interested in this Region to reduce the risk associated with and meet higher safety requirements.

Pipe sticking and wellbore stability problems are regarded as medium risk events, then new mitigation measures are not required given to existing controls can be verified as functional. These incidents were associated with the presence of shale sections in the Cretaceous formation of Ubarana (shales/marlstones) exposed in the last drilling phases (IV e V). The use of water-based drilling fluid caused swelling and sloughing of shales resulting in partial or total obstruction of the borehole diameter. Reaming and fishing operations executed in response to the reactive-rock-related problems were the most common way of NPT reported on the well folders. Some consequences include hole cleaning problems resulting from the accumulation of swollen rock blocks into the annular space, and potential loss of a well section as fish is found irretrievable requiring to sidetrack the well.

Finally, through obtained results, progress is made in understanding exploration risk in a largely unexplored area like BEM by providing useful and understandable information for interested operating companies to perform further risk studies. As a limitation of this work, only the oldest wells (before ANP creation) possessed well folders with drilling reports sufficiently detailed to perform a risk study. This reduced the number of examined wells from 14 to 8 . In addition, the old wells did not possess digitized logging data, which prevented them from integrating and/or validating the problem zones' depths. As a qualitative technique, the risk matrix is not particularly 
suitable for decision-making, due to the risk is expressed subjectively and on a coarse scale. Thus, several risk reduction measures may be taken without having any effect on the risk matrix. On the other hand, the results here presented are easy to comprehend for non-experts and provides a visual representation of the risk.

Future works shall include a complete and balanced risk assessment where the most critical risk events identified in this study to be quantitatively analyzed and, consequently, evaluate (against risk acceptance criteria). Risk evaluation is a key step for decision-making due to it involves proposing and assessing alternative mitigation measures. Additionally, including metocean conditions in future works is of great concern to reduce the exploratory risk as BEM is the high current environment. 


\section{REFERENCES}

ALLEN, D. W. Vortex-induced vibration of deepwater risers. Offshore Technology Conference. Anais...1998

ALVES, D. P. V. Análise sismoestratigráfica das bacias de Barreirinhas e do Ceará como ferramenta para estudos paleoceanográficos no Cenozoico na Margem Equatorial Brasileira. São Paulo: Universidade de São Paulo, 29 jun. 2018.

AMORIM JUNIOR, D. DE S. Metodologia para a redução de custos na perfuração de poços de petróleo e gás. São Paulo: Universidade de São Paulo, 22 set. 2008.

ANP. DVD-003800. Rio de Janeiro: ANP Banco de Dados de Exploracao e Producao. 2016. 1 DVD.

ANP. DVD-003801. Rio de Janeiro: ANP Banco de Dados de Exploracao e Producao. 2016. 1 DVD.

ANP. DVD-003802. Rio de Janeiro: ANP Banco de Dados de Exploracao e Producao. 2019. 1 DVD.

ANP. DVD-003803. Rio de Janeiro: ANP Banco de Dados de Exploracao e Producao. 2016. 1 DVD.

API. 580 Recommended Practice for Risk-Based Inspection. n. November, p. 96, 2009.

AVILA, R. M. Brazilian Equatorial Margin Prospectivity. ANP Open Acreage Brazil Oil and Gas Concession. Anais...2018

BARCELOS, A.; AWAD, S. P.; ASSUNCAO, R. B. Deepwater Activities Offshore Brazil: Evolution on Drilling TechnologyUniversity of Tulsa Centennial Petroleum Engineering SymposiumTulsa, OklahomaSociety of Petroleum Engineers, , 1994. Disponível em: <https://doi.org/10.2118/28004-MS>

\footnotetext{
BASTOS, I. P. Bacia do Ceará - Sumário Geológico e Setores em Oferta. [s.l: $\quad$ s.n.]. Disponível em: $<$ http://rodadas.anp.gov.br/arquivos/Round15/Mapas/Sumario_Geologico_R15_Cear a.pdf>.
}

\footnotetext{
BATISTA, C. Bacia Potiguar - Sumário Geológico e Setores em Oferta. [s.l: s.n.]. Disponível em: <http://rodadas.anp.gov.br/pt/concessao-de-blocosexploratorios-1>.
}

BENDER, A. A. et al. Integrating exploration tools to reduce risk. Oilfield Review, v. 22, n. 2, p. 4-13, 2010.

BHANDARI, J. et al. Risk analysis of deepwater drilling operations using 
Bayesian network. Journal of Loss Prevention in the Process Industries, v. 38, p. 11-23, 1 nov. 2015.

BRUCE, R. J.; SHIPP, R. C. Guidelines for Drillsite Selection and Near-Surface Drilling Hazard Surveys. IODP publications, n. February, p. 1-30, 2003.

CARTER, D. R.; ADAMS, N. J. Hydrogen Sulfide In The Drilling IndustrySPE Deep Drilling and Production SymposiumAmarillo, TexasSociety of Petroleum Engineers, , 1979. Disponível em: <https://doi.org/10.2118/7854-MS>

CHAE, K.-S.; LEE, J. W. Risk analysis and simulation for geologic storage of CO2. Proceedings of the World Congress on Advances in Civil, Environmental, and Materials Research, Incheon, Korea. Anais...2015

ERIVWO, O. E.; ADELEYE, O. A. Narrow Margin Drilling in Deepwater:
Solution ConceptsSPE Deepwater Drilling and Completions
ConferenceGalveston, Texas, USASociety of Petroleum Engineers, , 2012.
Disponível em: <https://doi.org/10.2118/156254-MS>

FAVERA, P. J. D. C. et al. New Exploration Frontiers of Brazil's Atlantic Margin: From Theory to Reality. Proceedings of Offshore Technology Conference (OTC), v. 24422, p. 1-11, 2013.

FONTANA, R. L.; MUSSUMECI, A. Hydrates Offshore Brazil. Annals of the New York Academy of Sciences, v. 715, n. 1, p. 106-113, 1 abr. 1994.

GARDNER, T. N.; COLE, M. W. Deepwater Drilling in High Current EnvironmentOffshore Technology ConferenceHouston, TexasOffshore Technology Conference, , 1982. Disponível em: <https://doi.org/10.4043/4316-MS>

GRABER, K. K. Guidelines for Site Survey and Safety. [s.I.] Ocean Drilling Program, 2007. v. //

HOVLAND, M. et al. Gas hydrate and free gas volumes in marine sediments: Example from the Niger Delta front. Marine and Petroleum Geology, 1997.

INTEGRATED OCEAN DRILLING PROGRAM. Active Proposals. Disponível em: <https://www.iodp.org/proposals/active-proposals>.

ISO. ISO 31000: 2009: Risk Management: Principles and Guidelines. [s.I.] International Organization for Standardization, 2009.

KETZER, M. et al. Gas Seeps at the Edge of the Gas Hydrate Stability Zone on Brazil's Continental Margin. Geosciences, v. 9, n. 5, p. 193, 2019.

KIRAN, R. et al. Identification and evaluation of well integrity and causes of failure of well integrity barriers (A review). Journal of Natural Gas Science and Engineering, v. 45, p. 511-526, 1 set. 2017. 
LAVROV, A. Chapter 1 - The Challenge of Lost Circulation. In: LAVROV, A. B. T.-L. C. (Ed.). . Lost circulation: mechanisms and solutions. Boston: Gulf Professional Publishing, 2016. p. 1-11.

MANDAVA, C.; LOCKRIDGE, M. D. Efficiency tracking system for a drilling rigUnited States, 2017.

MELLO, M. R. et al. New Deepwater Frontiers an Ocean Apart. GEO ExPro, v. Vol. 10, n. No. 2, p. 56-62, 2013.

NORSOK. Risk and emergency preparedness assessment - Norsok Standard Z-013. [s.I: s.n.].

OREDA. OREDA Handbook. 5. ed. [s.l: s.n.].

PRITCHARD, D. et al. Drilling hazard management: The value of risk assessment. World Oil, v. 231, n. 10, p. 43-52, 2010.

ROCHA, L. A.; AZEVEDO, C. Projetos de Poços de Petróleo: geopressões e assentamento de colunas de revestimentos. Rio de Janeiro, Brazil: Interciência, 2007.

ROCHA, L. A. S. et al. Fracture Pressure Gradient in DeepwaterIADC/SPE Asia Pacific Drilling Technology Conference and ExhibitionKuala Lumpur, MalaysiaSociety of Petroleum Engineers, , 2004. Disponível em: <https://doi.org/10.2118/88011-MS>

SAD, A. R. E. et al. Marine gas hydrates evidence along the Brazilian coast. Proc. AAPG international conference and exhibition. Rio de Janeiro, Brazil. Nov. Anais...1998

SILVEIRA, I. C. A. DA et al. A corrente do Brasil ao largo da costa leste brasileira. Revista Brasileira de Oceanografia, v. 48, n. 2, p. 171-183, 2000. 2011.

WERTHEIM, P. H. Brazil's equatorial margin offers new frontier. Offshore, 